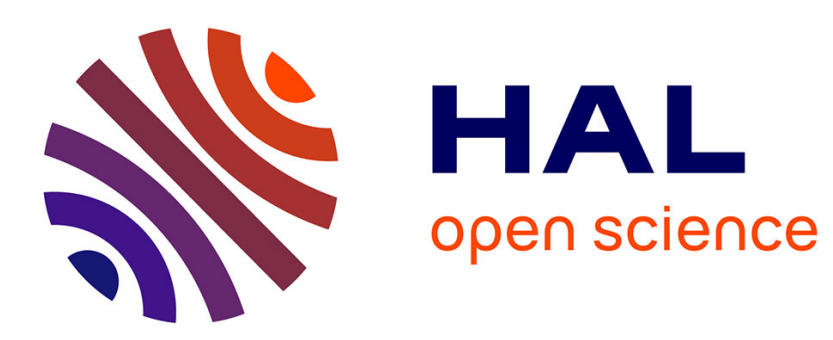

\title{
Effect of landscape connectivity on plant communities a review of response patterns
}

Léa Uroy, Aude Ernoult, Cendrine Mony

\section{To cite this version:}

Léa Uroy, Aude Ernoult, Cendrine Mony. Effect of landscape connectivity on plant communities a review of response patterns. Landscape Ecology, 2019, 34 (2), pp.203-225. 10.1007/s10980-019-007715. hal-02050502

\section{HAL Id: hal-02050502 https://hal-univ-rennes1.archives-ouvertes.fr/hal-02050502}

Submitted on 13 Mar 2019

HAL is a multi-disciplinary open access archive for the deposit and dissemination of scientific research documents, whether they are published or not. The documents may come from teaching and research institutions in France or abroad, or from public or private research centers.
L'archive ouverte pluridisciplinaire HAL, est destinée au dépôt et à la diffusion de documents scientifiques de niveau recherche, publiés ou non, émanant des établissements d'enseignement et de recherche français ou étrangers, des laboratoires publics ou privés. 
1 Title:

2 Effect of landscape connectivity on plant communities: a review of response patterns

3

$4 \quad$ Uroy L. ${ }^{1}$, Ernoult A. ${ }^{1}$, Mony C. ${ }^{1}$

5

6 1: UMR CNRS ECOBIO, University of Rennes, Avenue du Général Leclerc, 35042 Rennes

7 Cedex, France

8

9 Corresponding author information:

10 Léa Uroy

11 Phone number: $(+33) 6.34 .25 .62 .22$

12 E-mail address: lea.uroy@univ-rennes1.fr

13 
Abstract:

15 Context. Fragmentation in agricultural landscapes is considered as a major threat to biodiversity. Thus, ecological corridors are deployed at multiple scales to increase connectivity. However, there is limited consensus about their efficiency, especially for plants. Objectives. We assimilated existing knowledge to assess whether and how landscape connectivity impacts plant communities.

20 Methods. We reviewed published literature across more than 20 years, providing an overview on the influence of connectivity on plant communities. Results. We found that landscape connectivity has a varying and complex influence on the composition and diversity of plant communities (i.e. community taxonomic structure), due to the multiplicity of factors that modulate its effect. Our understanding of how of landscape connectivity impacts the dispersal of plants is improved by using biological traits (i.e. community functional structure). Finally, we showed that landscape connectivity promotes actual dispersal between connected communities.

Conclusions. This review emphasises the pertinence of trait-based and actual dispersal approaches to improve our understanding and ability to predict the effect of connectivity loss on plant communities, allowing us to identify new prospects for future research.

32 Keywords: plant communities, traits, seed dispersal, actual dispersal, ecological corridors 


\section{Introduction}

Anthropogenic activities, including urbanization and agricultural intensification, present major threats to biodiversity, notably through their effects on landscape fragmentation (Stoate et al. 2001; Katoh et al. 2009; Haddad et al. 2015). Landscape fragmentation impacts the populations of plants through two distinct effects: habitat loss (i.e. a decrease in habitat area) and connectivity loss (i.e. decreased plant dispersal among remnant patches; Taylor et al. 1993) (Fahrig 2003; Fischer and Lindenmayer 2007). Because of their sessile way of life, plants are particularly vulnerable to these effects, and many studies have reported a strong decline in floristic diversity in fragmented agricultural landscapes (Andreasen et al. 1996; Kleijn and Verbeek 2000; Luoto et al. 2003; Baessler and Klotz 2006; Kleijn et al. 2009). The effect of habitat area on plant diversity is well established (e.g. Scanlan 1981; Dzwonko and Loster 1988; Zacharias and Brandes 1990; Honnay et al. 1999; Godefroid and Koedam 2003; Gignac and Dale 2007). Small patch size increases extinction risk by reducing carrying capacity. Consequently, populations in smaller habitats are more susceptible to extinction, due to demographic stochasticity (MacArthur and Wilson 1967). Only in the last two decades have studies begun investigating how connectivity loss affects plant diversity and the corresponding mechanisms; consequently, there is a low level of synthesis of existing knowledge.

Depending on the intensity of connectivity loss, the spatial distribution of species might range from a continuous population to a set of isolated populations with a metapopulation structure (i.e. a network of local populations linked by dispersal fluxes, Hanski 1994) as an intermediate case. More recently, the metapopulation concept has been extended to the community level (i.e. metacommunity concept, Leibold et al. 2004). A metacommunity refers to a set of local communities that are linked by the dispersal of multiple potentially interacting species (Wilson 1992). The strong interest in metacommunity theory has given rise to four paradigms to describe metacommunities: i) species sorting (i.e. habitat patches are 
environmentally heterogeneous with high enough dispersal to enable species to fill niches within habitat patches because of niche diversification); ii) mass effects (i.e. habitat patches are environmentally heterogeneous and high dispersal enough override local dynamics); (iii) patch dynamics (i.e. habitat patches are environmentally homogeneous and species differ in their ability to disperse. Along a colonisation-competition trade-off, successful colonisers outcompete poor competitors and vice versa); and iv) neutral models (i.e. species do not differ in their fitness or niche) in the case of ecological drift (Leibold et al. 2004; Logue et al. 2011). These models formulate different hypotheses on the relative importance of dispersal, habitat heterogeneity and interactions between species in the structuring mechanisms of local communities (Leibold et al. 2004; Logue et al. 2011). Plant disperse passively between habitat patches via pollen and/or seeds. However, this process is only successful if habitat patches are sufficiently connected (Fahrig and Merriam 1985; Bowne and Bowers 2004); in other words, plant dispersal among source patches must be facilitated by suitable landscape elements (Taylor et al. 1993). Landscape connectivity might be promoted by the occurrence of corridors between favourable patches, such as continuous, relatively narrow, habitat bands connecting two patches (Burel and Baudry 1999). However, connectivity might also include nonlinear or discontinuous landscape features that are permeable to plant dispersal (Beier and Noss 1998; Chetkiewicz et al. 2006). Thus, high connectivity between habitat patches might reduce the adverse effects of fragmentation by facilitating genetic fluxes among local populations through plant dispersal (Wilson and Willis 1975), which contrasts with animals for which all movements is concerned. However, the ability of plants to disperse in fragmented landscapes might depend on their dispersal strategy, with some being more or less able to promote frequent long-distance dispersal events. For instance, if wind-dispersal or water-dispersal is generally achieved over a long distance, depending on the intensity of the wind or current and the adaptations of the seeds, gravity-dispersed plants (i.e. barochory) are dispersed more locally (Nathan et al. 2002; 

Tackenberg 2003; Vittoz and Engler 2007; Pollux et al. 2009; Nilsson et al. 2010). Animaldispersed plants are dispersed over short distances of $<100 \mathrm{~m}$ (e.g. by small animals, such as insects, small mammals and some bird species) to long distances of several kilometres (e.g. by large or migratory animals; Vittoz and Engler 2007). These vectors might be influenced differently by landscape elements and, in turn, might influence plant responses to connectivity loss. Within a certain type of dispersal mode, plant species might represent a large range of capacities to disperse with respect to quantity (i.e. number of potential dispersers) and distance (i.e. dispersal range) (Johst et al. 2002; Nathan 2006; Auffret et al. 2017), which might decrease or increase their chance to disperse. These responses involve a selection of particular biological traits (i.e. morphological, biochemical, physiological, structural, phonological or behavioural characteristics of organisms that influence performance or fitness, Violle et al. 2007). At the plant community scale, analyses of how these traits respond to connectivity might help us to understand the processes that are involved, which would facilitate a more mechanistic analysis of plant assembly in fragmented landscapes.

Because plants are sessile, the effect of connectivity on plant assemblages might be time-dependent, with responses reflecting a relaxation time (i.e. the time taken for a community of species to reach a new equilibrium after an environmental disturbance, Diamond 1972; Kuussaari et al. 2009). By extension, the response of plant to connectivity might also reflect an extinction debt, which is defined as the number or proportion of extant species predicted to become extinct as the species community reaches a new equilibrium after an environmental disturbance (Tilman et al. 1994; Ovaskainen and Hanski 2002; Kuussaari et al. 2009). The response of plant assemblages to connectivity might also reflect an immigration lag, i.e. the time that has elapsed between an immigration-committing forcing event (e.g. increasing connectivity) and the establishment of an immigrating species (Jackson and Sax 2010). By extension, this phenomenon would lead to immigration credit (Jackson and Sax 2010), which 
108 is defined as the number of species committed to eventual immigration following a forcing event (Kuussaari et al. 2009). In addition, temporal lags in extinction and immigration are mediated by variation in traits across species under experimental situations (Haddad et al. 2015). Thus, considering the role of historical connectivity on the composition and diversity of

112 plant communities and how traits mediate the delayed response of plant might improve our 113 understanding of how plant species respond to connectivity loss. Metacommunity theory recognizes that established local communities may additionally be driven by stochasticity (which is eventually spatially correlated), local patch conditions and species traits (i.e. colonisation vs. competition trade-offs) (Mouquet and Loreau 2003). As a

117 result, recent studies argued that assessing how connectivity affects established communities in 118 habitat patches is subject to bias. Indeed, once a propagule arrives in a patch, its ability to establish depends on a large range of local factors linked to local habitat quality (e.g. management, land-use history, Brudvig 2016) and biotic interactions (e.g. plant-plant, plant-

121 animal, plant-soil interactions, Archer and Pyke 1991; Pyke and Archer 1991; Fukami and 122 Nakajima 2013). Therefore, it might be difficult to disentangle the effects of landscape 123 connectivity and local filters. In addition, the increase of connectivity might indirectly affect 124 the establishment and coexistence of plants in the community by promoting the displacement 125 of: i) organisms that might predate on (e.g. herbivores and granivorous species, Orrock et al. 126 2003; Orrock and Damschen 2005; Rossetti et al. 2017) or parasitize seeds (e.g. Sullivan et al.

127 2011), or ii) strong competitors that once, they arrived in a local patch, drive local biotic 128 interactions and outcompete less competitive species (Simberloff and Cox 1987; Mouquet and 129 Loreau 2003, e.g. exotic invasive plant species, Minor et al. 2009; Minor and Gardner 2011). 130 To assess the direct effect of connectivity on seed dispersal, Calabrese and Fagan (2004) 131 proposed the concept of actual functional connectivity (Fig. 1 and Box 1). This concept is based 132 on the direct assessment of seed fluxes depending on habitat connectivity. This form of direct 
assessment might reflect the effect of connectivity on the process of dispersal alone, independent of other local factors that are difficult to standardise.

The number of studies analysing the influence of landscape connectivity on biodiversity has increased considerably since the early part of the 21st century (Ayram et al. 2016). To facilitate the identification of general patterns, reviews have been complied on how connectivity affects global biodiversity (Murphy and Lovett-Doust 2004; Haddad and Tewksbury 2006; Gilbert-Norton et al. 2010; Haddad et al. 2011, 2015; Fletcher et al. 2016). These reviews have provided evidences of the effect of connectivity at different levels of organization (individuals, populations and communities) essentially through experimental approaches (Haddad and Tewksbury 2006; Haddad et al. 2011, 2015) or sometimes coupled with correlatives ones (Murphy and Lovett-Doust 2004; Gilbert-Norton et al. 2010; Fletcher et al. 2016). However, these reviews mostly focus on animal biodiversity. When these reviews consider existing literature on plants, the response of plants to connectivity is usually often assessed at the population level and under experimental conditions and does not take into account the traits of plant species (Murphy and Lovett-Doust 2004; Gilbert-Norton et al. 2010; Haddad et al. 2011, 2015; Fletcher et al. 2016). As a result, our understanding of the role of connectivity for plants remains limited, especially at the community level. The effect of connectivity on plant communities cannot be predicted from its effect on plant populations and individuals, as communities incorporate distinct properties linked to their dynamics such as priority effects (Fukami 2015) and successional changes in species diversity over time. This lack of knowledge may be particularly problematic for the conservation of plant biodiversity, which aims to go beyond single-species approaches (Groves et al. 2002).

In the present review, we aimed to provide a synthesis of existing scientific knowledge on how connectivity loss influences plant communities. To achieve this synthesis, we only considered studies that assessed connectivity and plant species responses at the community 
158 level. Connectivity was analysed under experimental approaches through the presence or

159 absence of an experimentally-created corridor between patches (Fig. 1 and Box 1) or under

160 correlative approaches using quantitative indices. Quantitative connectivity assessments were

161 based on isolation metrics such as Euclidean distance, structural connectivity indices (see

162 various examples in the main text), least-cost distance and resistance distance (respectively

163 derived from graph and circuit theory, potential functional connectivity) (Fig. 1 and Box 1).

164 This approach included: i) analysis of individual species responses across most species of the

165 community and, ii) aggregated measures across most species of a given community (for more

166 details, see Appendix S1).

167 Specifically, we present how landscape connectivity influences the richness and

168 composition of plant communities (section 1). We also review how plants respond to

169 connectivity from a mechanistic perspective (related to dispersal vector mode and plant

170 dispersal traits), to demonstrate that traits may help to define species sensitivity to connectivity

171 loss (section 2). We also evaluate how time affects plant taxonomic and functional response to

172 connectivity (section 3). Finally, we review how connectivity drives actual dispersal (section

173 4). We conclude that landscape connectivity influences plant communities as a filter for species

174 and traits. We also emphasize that trait-based and actual dispersal approaches are the most 175 relevant for predicting how connectivity loss affects plant communities. We use our findings to 176 suggest further research needs.

178 Contrasted effect of landscape connectivity on plant community taxonomic structure

179 Higher connectivity facilitates plant dispersal and thus decreases the probability of local 180 extinction. Thus, high connectivity might influence the taxonomic structure of communities 181 (i.e. the composition and diversity of plant communities), increasing species diversity and 182 similarity in composition between connected patches. 
185 How connectivity affects species diversity has been a central question in landscape ecology over the last two decades. Early studies tested this question by comparing pairs of patches that were (or not) connected through a corridor. The effect of the presence/absence of a corridor on

188 plant diversity has been, for instance, addressed through the experimental manipulation of connectivity between habitat patches. One of the most well-known designs is based at Savannah River Site (South Carolina, USA), which supports a range of landscape designs embedded in a forest matrix. In this experimental design, each landscape is composed of a central patch that is connected to one peripheral patch by a corridor, and a peripheral patch that is not connected to

193 the central patch (Box 2). In this design, patches connected by a corridor displayed a richness 194 higher than 20\% compared to the non-connected patches (Damschen et al. 2006). Plant species richness also increases from 10 to $18 \%$ in the matrix surrounding the connected patches by a mass spatial effect (Brudvig et al. 2009); thus, the presence of corridors might positively impact adjacent landscape elements.

Another set of studies used connectivity measurements based on the Euclidean distance

199 or on the permeability of the landscape elements to dispersal. In the latter case, these measurements incorporate the physical attributes of the landscape with or without information about the organism of interest (structural or potential functional connectivity) and assess the degree of connectivity for each habitat patch (Fig. 1 and Box 1). Depending on the ecosystem 203 type, landscape connectivity has a contrasting effect on community diversity. For instance, local 204 heathland species richness increases with structural connectivity [measured through the Incidence Function Model index (IFM index) based on the area and the Euclidean distance to other patches of similar habitat type, Hanski 1994; Moilanen and Nieminen 2002)] (Piessens et al. 2004), whereas structural connectivity does not influence the richness and the density of 
species (i.e. average number of species per square meter) of local plant communities in seminatural grasslands (Lindborg and Eriksson 2004; Helm et al. 2006; Cousins et al. 2007). Lindborg and Eriksson (2004) demonstrated that this absence of a relationship with connectivity was maintained at different spatial scales (1 $\mathrm{km}$ or $2 \mathrm{~km}$ radius). Only one study demonstrated a negative influence of connectivity on local plant community richness in riverine wetlands. Specifically, Bornette et al. (1998) reported that high connectivity decreases species

214 richness when assessing structural surficial connectivity between cut-off channels and the river by quantifying the overflows and blackflows of rivers into cut-off channels. Under these conditions, high connectivity impedes recruitment due to over-frequent flood scouring or due to nutrient-rich and turbid surficial waters being supplied to the wetland, which reduces species 218 richness.

Most studies investigating how landscape connectivity affects plant species communities measure species richness at the alpha-scale (i.e. local diversity) (Bennett et al. 2006). In comparison, studies carried out at a gamma-scale (i.e. landscape diversity) remain limited. For instance, Favre-Bac et al. (2014) reported that the structural connectivity of ditch networks (i.e. number of disconnected network units) decreases species richness of ditch bank 224 communities when analysing 27 square sites of $500 \times 500 \mathrm{~m}$. This result might be attributed to the influence of landscape heterogeneity, which might mitigate the negative effects of habitat fragmentation (Tscharntke et al. 2012).

Overall, no general pattern has been detected on the positive effect of corridors on plant 228 diversity through correlative approaches, contrary to experimental approaches (Haddad et al. 229 2015). Two possible explanations why correlative studies have failed to demonstrate a general 230 pattern are: i) the too low suitability and number of available habitat patches for plants to 231 colonise and establish, and ii) the lack of consideration of the quality (e.g. management 232 practice) of the landscape elements. These studies assessed connectivity through the presence 
and identity of landscape elements to determine their permeability to dispersal, overlooking the

234 potential effect of the quality of these elements on their permeability.

\section{Plant community composition}

In fragmented landscapes, remnant habitat patches might be highly heterogeneous, causing

238 strong divergence in the composition of local communities (Tscharntke et al. 2012). In addition,

239 the amount of dispersal between remnant patches might strongly impact these dynamics

240 (Mouquet and Loreau 2003; Mouquet et al. 2006). When isolated, seed limitation is expected

241 to enhance divergence between local communities at the metacommunity scale, further

242 reducing their similarity (Mouquet and Loreau 2003; Tscharntke et al. 2012). A particular case

243 of dissimilarity in species composition, the nested subset (i.e. a community in which the species

244 present at species-poor sites constitute subsets of those from species-rich sites, Patterson and

245 Atmar 1986) was highlighted in heathland communities by Piessens et al. (2004). In these

246 systems, dissimilarity increases as structural connectivity decreases. The higher the landscape

247 structural connectivity, the higher the similarity of the community. Similar results were also

248 reported for communities of linear landscape elements, such as field margins, road verges and

249 ditches (Thiele et al. 2017). For instance, Thiele et al. (2017) tested three types of connectivity

250 metrics (Euclidian distance, potential functional connectivity: least-cost distance and resistance

251 distance, see Fig. 1 and Box 1.), and demonstrated that the results were independent of the way

252 that connectivity was evaluated.

253 Within local communities, fragmentation theoretically decreases species richness

254 because it acts as a strong ecological filter, selecting for species that are able to disperse and

255 survive in isolated patches. Thus, Haddad and Tewksbury (2006) theorised that specialist

256 species should be more affected by connectivity loss than generalist species, because the latter

257 group might perceive corridors as being of lower quality compared to the surrounding habitats. 
Isolated patches might contain more generalist than specialist species in plant communities compared to connected patches. In grassland communities, specialist species decrease to a greater extent compared to generalist species in response to the loss of structural connectivity (Adriaens et al. 2006; Brückmann et al. 2010; Evju et al. 2015). Adriaens et al. (2006) reported

that only specialist species are impacted by a change to the structural connectivity (assessed with the IFM index) of grasslands, with the mean number of species per site decreasing by about 37\%. Similar results were obtained by Brückmann et al. (2010) and Evju et al. (2015). For instance, Brückmann et al. (2010) recorded a decrease of $24-37 \%$ in the richness of specialist species in grasslands in response to a total loss of structural connectivity (IFM index), whereas generalists were not affected. Therefore, the effect of connectivity on plant species depends on the degree of specialisation. Thus, different types of ecological corridors might interact in a landscape. For instance, grassland corridors between forest patches might reinforce the effect of forest corridors in connected forest patches only when considering generalist species in forests. These interactions between corridor types might rank from potential complementarity for generalist species to potential antagonism for specialist species, in which 273 one ecological corridor type is favourable while the other constitutes a barrier. Thus, it is 274 important to consider how complementary between the different types of ecological corridors are in studies linking connectivity to plant communities. This consideration could be coupled with the improved modelling of ecological corridor types through the use of SDMs (Species

277 Distribution Models; Guisan and Thuiller 2005), which represent a promising approach to 278 assess the permeability of landscape features to dispersal (e.g. Morato et al. 2014), rather than 279 expert knowledge (Rayfield et al. 2010; Spear et al. 2010; Zeller et al. 2012; Koen et al. 2012). 
Because of the contrasting results provided by taxonomic approaches, there is a growing need

283 to predict how plant communities respond to changes in connectivity. Analyses based on the 284 functional structure of communities (i.e. the composition and diversity of traits) might help to 285 improve our understanding of species responses by providing a mechanistic explanation (for a 286 detailed synthesis of these studies, see Table 1).

\section{Dispersal vector mode}

289 Studies using trait-based approaches initially focused on how plant dispersal vectors influence their responses to connectivity. Plant dispersal vectors determine plant dispersal distance. For

291 instance, dispersal is close to the parent plant for gravity-dispersed species, and up to several 292 hundred metres or even kilometres for animal-, wind- and water- dispersed species (Sorensen 293 1986; Nathan et al. 2002; Tackenberg 2003; Vittoz and Engler 2007; Pollux et al. 2009; Nilsson 294 et al. 2010).

Animal-dispersal is oriented, and depends on animal behaviour and movement in the 296 landscape. There is broad consensus that animal movement is facilitated by landscape 297 connectivity (Murphy and Lovett-Doust 2004; Haddad and Tewksbury 2006; Gilbert-Norton et 298 al. 2010; Haddad et al. 2011, 2015; Fletcher et al. 2016); thus, animal-dispersed plant species 299 might be largely dependent on landscape connectivity. It is more difficult to predict how 300 connectivity affects wind-dispersed plants, as this type of dispersal is made at random or occurs 301 in relation to the dominant wind direction. Differences in these two plant dispersal vectors 302 might lead to different responses to connectivity. Damschen et al. (2008) surveyed the species 303 richness of bird-dispersed and wind-dispersed species over a seven-year period in the Savannah 304 River Site (Box 2). The authors demonstrated that, for both functional groups, the richness of 305 communities was lower in unconnected versus connected patches. However, this difference in 306 richness reached an asymptote for bird-dispersed species after five years, but not for wind- 
dispersed species. This asymptote is due to the behaviour of birds that regularly visit all patches

308 of the experimental design. As a result, even isolated patches occasionally receive new 309 colonists, reducing the difference in species richness between connected and unconnected 310 patches over time. By contrast, the presence of an open corridor affects wind dynamics by 311 redirecting and promoting airflow and "ejection hotspots" (i.e. locations in which seeds have a 312 relatively high probability of being uplifted) in connected patches. These processes increase the 313 likelihood of seed uplift, and, therefore, the likelihood of seed redirection and bellow among 314 connected patches (Damschen et al. 2014). As a result, the difference in species richness 315 between connected and unconnected patches continues to increase over time. Based on the same 316 design, Brudvig et al. (2009) showed that the richness of animal-dispersed species increased by $317 \quad 13-19 \%$ per $100 \mathrm{~m}^{2}$ in the surrounding matrix in response to connectivity, whereas no mass 318 spatial effect was found for wind-dispersed species. This result was due to a barrier effect of 319 the surrounding matrix of dense pine plantations on wind-dispersed species (Damschen et al. 320 2014). In contrast, animals were not restricted to the experimental design, moving in and out of 321 patches to the matrix, resulting in their contributing to the dispersal of plants. When assessed 322 in more correlative approaches, no particular influence of landscape connectivity (Euclidean 323 distance, structural and potential functional connectivity) was demonstrated on animal324 (external, internal and by ants) and wind-dispersed species (Piessens et al. 2005; Lindborg 2007; Evju et al. 2015; Thiele et al. 2017, but see contrasting results provided by Verheyen et al. (2004) who only considered vertebrate-animal dispersal and wind dispersal), despite their 327 potential for long-distance dispersal. This finding suggests that, in real systems, the effect of 328 connectivity on the functional structure of plant communities is overshadowed by other characteristics of the landscape, such as patch shape, which influences the quantity of the

330 interface with other habitats (e.g. Arellano-Rivas et al. 2016) or the fine-scale structuring of 
corridors. In turn, this phenomenon influences the degree of permeability for animal- (e.g. animal vector behavioural changes) and wind- (e.g. wind dynamics changes) dispersed species. Another dispersal mode contributing to long-distance dispersal is hydrochory. Many studies have investigated the role of water dispersal in structuring plant communities, in both flowing and stagnant systems (for a review, see Nilsson et al. 2010). However, very few studies present the effect of connectivity on water-dispersed plant communities. Favre-Bac et al. (2014) showed that the richness of water-dispersed species at the landscape scale was independent of ditch network connectivity, regardless of the measures of connectivity considered (i.e. total ditch length, number of culverts, number of intersections and number of disconnected ditch network subunits). However, similarity within local water-dispersed communities decreased with the number of intersections, suggesting that these intersections act as barriers to dispersal and cause a decrease of seed fluxes between communities (Favre-Bac et al. 2014). Similar results were obtained by Piessens et al. (2005).

Other modes have been less studied, mostly because they were supposed to contribute less to long-distance dispersal and, therefore, to plant sensitivity to connectivity. Nonetheless, several studies have demonstrated a positive response of unassisted species (i.e. species without dispersal structures, mostly gravity-dispersed species) in response to connectivity by both experimental (Damschen et al. 2008) and correlative (Kolb and Diekmann 2005; Thiele et al. 2017) approaches. Damschen et al. (2008) demonstrated that the difference in unassisted species richness between connected and non-connected patches was been six-fold greater after seven years. A similar response was obtained by Thiele et al. (2017). The authors obtained a positive relationship between connectivity (Euclidean distance and potential functional connectivity) and similarity for unassisted species communities of linear landscape elements (field margins, ditches, road verges). Despite the increase in unassisted species richness (Damschen et al. 2008), the relative proportion of these species does not seem to be influenced 
by connectivity within communities. When using a correlative approach, Lindborg (2007) reported that the proportion of unassisted species in semi-natural grasslands was independent of structural connectivity (IFM index). These results corroborate the work of Piessens et al. (2005), who demonstrated that unassisted species are not sensitive to structural connectivity. However, the dispersal mechanisms explaining the differential responses of unassisted species in terms of richness and relative proportion to landscape connectivity have yet to be clarified. As suggested by Damschen et al. (2008), these results challenge the notion that unassisted species are truly unassisted in their dispersal, corroborating evidence from other studies

364 (Vellend et al. 2003; Higgins et al. 2003).

\section{Plant dispersal traits}

367 Beyond the dispersal mode, precise combinations of traits might favour the ability of plants to 368 produce a large number of potential dispersers (e.g. seed number, vegetative fragmentation), and to be dispersed over long distances (e.g. seed mass, low terminal velocity, high gut retention), with both characteristics corresponding to the definition of species dispersal ability

371 (Johst et al. 2002; Nathan 2006; Auffret et al. 2017). Thus, species with traits promoting high 372 dispersal ability might be less sensitive to connectivity loss.

\section{Emergent groups to connectivity}

375 Initially, studies that analysed the dispersal traits of plants in response to connectivity were 376 based on a functional group approach similar to the one proposed by Lavorel et al. (1997); 377 namely, emergent groups are groups of species that reflect natural correlation of biological 378 attributes. By coupling changes to plant occurrence or abundance along the gradient of connectivity and trait-data on plant species, these studies analysed the syndrome of traits that characterise plant sensitivity or resistance to connectivity. 
One of the very first studies on emergent groups focused on forest communities (Kolb and Diekmann 2005). These authors analysed species biological traits for two groups of plants: one corresponding to sensitive plants (i.e. the occurrence of which decreases with structural connectivity loss, evaluated through IFM index) and one corresponding to resistant plants (i.e. the occurrence of which is not impacted by structural connectivity loss). Sensitive plants were characterised by high clonality, few and heavy seeds and unassisted dispersal. Resistant plants displayed assisted dispersal, no or little clonal growth and produced many and thin seeds. Traits promoting local establishment instead of long-distance dispersal contributed to plant sensitivity to connectivity loss. Using a similar approach, Adriaens et al. (2006) classified specialist species from calcareous grasslands, using 16 life-history traits, and detected four different groups. Higher structural landscape connectivity increased species richness in only one of the groups, whereas the other groups were not affected. This group contains species that are characterised by a perennial rosette with no vegetative multiplication and no long-distance dispersal mode (i.e. ballistochory, ant-dispersed seeds, barochory). Such species are more sensitive to connectivity loss, as they are less likely to recolonise and establish in patches after extinction. The three other groups were not impacted by connectivity loss. These groups included orchids (characterised by short flowering, low mass seeds and wind-dispersal), halfrosette species (with fruity dispersules and seeds, with optional vegetative reproduction mechanisms) and annual species (early and long flowering small autogamous annuals, low mass and no long-distance dispersal mode). However, the use of a large set of many traits, including

401 ecological traits (i.e. linked with species niche), makes it difficult to disentangle the effect of 402 dispersal traits from the other traits when evaluating how species respond to connectivity loss. 403

\section{$\underline{\text { Response traits to connectivity }}$}


Studies over the last two decades have focused on traits considered individually to define 406 individual response traits (i.e. traits reflecting the response of organisms to a given environmental factor, Lavorel et al. 1997) to landscape connectivity. This approach differs from the emergent group approach by analysing one trait at a time to characterise species sensitivity to connectivity. Species that displayed similar trait values in response to connectivity are designed as response groups of plants (i.e. group of species that respond in similar ways to a given environmental factor for a given trait, Lavorel et al. 1997). forest communities to connectivity loss through the regression coefficient derived from the 414 regression model, using patch occupancy as the dependent variable and structural connectivity 415 (modified version of IFM index that incorporates patch age, Verheyen et al. 2004) as the 416 independent variable. Species characterised by lower numbers of seeds (and thus, a low number 417 of potential dispersers) were sensitive to connectivity loss. In ruderal (brownfields) 418 communities, Schleicher et al. (2011) demonstrated that wind-dispersed species sensitive to 419 structural connectivity loss are those characterised by lower seed number and higher terminal 420 velocity (i.e. rate at which a seed can fall in still air). High terminal velocity corresponds to 421 short dispersal range by reducing the probability of dispersal by air uplift, while reduced seed number corresponds to a low number of potential dispersers. Consequently, both trait expressions are indicative of low dispersal ability. Sensitive and resistant plants were the most

424 differentiated using a quotient of the seed number divided by terminal velocity. Moreover, the 425 authors found that the clearest differentiation between the two connectivity response groups 426 was obtained when combining seed number and terminal velocity in a quotient. These results 427 highlight a compensatory relationship between these two traits; high dispersal distance might 428 counterbalance low numbers of dispersers and vice versa. Favre-Bac et al. (2017a) used traits 429 directly linked to water-dispersal to analyse how ditch communities respond to connectivity 
loss. The authors demonstrated that water-dispersed species that are highly sensitive to structural connectivity loss are characterised by short and round seeds with low mass and low

432 buoyancy (Favre-Bac et al. 2017a). Low buoyancy does not favour long-distance dispersal in 433 low current systems because species do not tolerate long or frequent retention events when

434 being dispersed. The authors also demonstrated the role of seed form on the probability of being 435 retained by obstacles in stagnant ditches during dispersal events. In this case, long and thin 436 seeds might be better aligned to flow direction, and succeed better in passing obstacles, such as 437 culverts and intersections (De Ryck et al. 2012). This type of study advanced our understanding 438 of the factors that induce dispersal in the studied system, providing some predictions on the 439 mechanisms causing species resistance in less connected networks.

440 Some studies demonstrated that connectivity responses are associated to traits linked 441 with the ability of plants to establish in habitat patches. For instance, Favre-Bac et al. (2017a) 442 reported that, in highly branched ditch networks (i.e. where intersections constitute obstacles to 443 dispersal), the most resistant plants had higher seed germination rates. This higher seed 444 germination rate increased their ability to develop when blocked by obstacles during dispersal.

445 Other traits linked to further steps of plant growth, such as competition (for instance, plant 446 height) and duration of growth (life-cycle duration), were also investigated. It was found that 447 species with lower competition capacity and short life-cycles (in temperate forest communities, 448 Verheyen et al. 2004, in heathland communities, Piessens et al. 2004, 2005; in dry calcareous 449 grasslands communities, Evju et al. 2015) are more sensitive to the loss of structural 450 connectivity. Therefore, it is important to develop approaches that take dispersal traits into account. 453 Such approaches are expected to complement and fill knowledge gaps on existing work based 454 on vector-types. Transposing the conceptual framework of response traits developed by Lavorel 
et al. (1997) to landscape ecology represents a promising avenue towards understanding and

456 predicting plant community responses to changes in connectivity.

\section{Community weighted mean traits and functional diversity}

459 Studies over the last 15 years on community ecology have developed other methods to describe

460 the functional structure of plant communities. These methods include aggregated measures quantifying the community the mean (i.e. community weighted mean traits) and range of trait values (functional diversity, for review, see Mouchet et al. 2010). In response to local factors, environmental filtering leads to convergent trait values that are adapted to environmental characteristics (van der Valk 1981; Weiher and Keddy 1995; Grime 2006). In contrast, biotic filtering can lead to: i) divergent trait values within communities (limiting similarity theory, MacArthur and Levins 1967; Grime 2006), leading to niche differentiation, or ii) convergent trait values within communities (competitive hierarchy theory, Herben and Goldberg 2014) due to the competitive exclusion of less competitive species. Transposition of these theories to the landscape scale is a promising research avenue in functional ecology. In response to reduced connectivity, plant communities at the landscape level should be filtered toward trait syndromes that promote high dispersal ability (i.e. low functional diversity and weighted mean trait values converge toward high seed number or traits promoting long-distance dispersal). scale depending on landscape characteristics is still at an early stage. To our knowledge, only 475 one study has used this highly promising approach (Favre-Bac et al. 2017b). The authors 476 demonstrated that lower ditch network connectivity induces convergent trait values toward 477 small seed production and high seed buoyancy. Higher seed buoyancy is particularity 478 favourable for successfully passing culverts, which constitute barriers (Soomers et al. 2010), 479 because seeds might persist until water level changes, wind strength or wind direction enables 
them to continue moving downstream. In comparison, lower seed production indicates that species invest heavily in vegetative growth, consolidating isolated local populations (Stöcklin and Winkler 2004). By contrast, higher connectivity in ditch networks reduces this filtering effect, or, even, leads to divergent trait values in seed mass. Consequently, in widely connected landscapes, several strategies coexist across local communities constituting the metacommunity. Higher seed weight provides more resources to guarantee growth during the early stages of establishment (Cornelissen et al. 2003), which mostly depend on competitive interactions with other plants within the local community. This local biotic filter favours the dissimilarity of plant traits involved in harvesting resources through the niche-partitioning effect (limiting similarity, MacArthur and Levins 1967; Pacala and Tilman 1994). These results demonstrate that, at the gamma scale, reduced connectivity acts as a filter on the dispersal traits of plant species involved in resistance to connectivity loss.

\section{Contribution of functional traits towards improving landscape connectivity models}

Trait-based studies provide a better understanding of the mechanisms involved in how plants respond to connectivity. Thus, by integrating plant traits in landscape connectivity modelling,

496 a more accurate prediction of the responses of species to connectivity loss should be obtained. This approach has been facilitated by the development of potential functional connectivity models (Fig. 1 and Box 1) that account for species dispersal distance in addition to the cost of species to cross over landscape features such as those of Pascual-Hortal and Saura (2006,

500 Integral Index of Connectivity, IIC) and Saura and Pascual-Hortal (2007, Probability of 501 Connectivity, PC). The two indices - IIC and PC - are based on different assumptions about the probability of connection between two considered patches (binary or probabilistic, respectively). However, only a few studies have used this type of graph-based connectivity 
504 index for plants (see García-Feced et al. 2011; Aavik et al. 2014). Thus, these approaches need 505 to be generalised.

507 Effect of time on the response of plants to connectivity

508 Historical landscape connectivity drives the taxonomic structure of plant communities

509 Most studies have overlooked the potential effect of relaxation time when analysing the

510 influence of connectivity on plant communities. However, this effect has been detected in 511 grassland communities. For example, Helm et al. (2006) showed that the alpha richness of 512 specialist calcareous grasslands is independent of their current structural connectivity, but is 513 dependent on their connectivity 70 years ago (i.e. dependent on the state of the landscape before 514 drastic habitat loss and connectivity loss). These results strongly support the concept that some plant communities are mostly composed of species that have the ability to resist to fragmentation by persisting without completing the whole life cycle (i.e. with no sexual 517 reproduction stages, Eriksson 1996). Grassland plant communities are indeed mostly composed 518 of perennial plants with long-lived vegetative life-cycle, and may then survive for decades after environmental changes (Eriksson 1996). Lindborg and Eriksson (2004) also detected a response of alpha diversity (richness and density) to landscape structural connectivity older than 50 years and 100 years ago in semi natural grasslands. The authors demonstrated an interactive effect between time and spatial resolution. A positive effect of connectivity 50 years ago was only detected for alpha diversity at the smaller scale (1 km radius); however, a positive effect of connectivity 100 years ago was detected at both scales considered $(1 \mathrm{~km}$ radius and $2 \mathrm{~km}$ radius). The presence of a relaxation time following an environmental perturbation might have indirect consequences on the biological scale of the response. For instance, Cousins and Vanhoenacker (2011) demonstrated that the gamma diversity of semi-grassland ecosystems 528 decreases more slowly after a decline in grasslands abundance in the landscape compared to alpha diversity. Although no study has yet investigated the difference in the response of alpha 
and gamma diversity on historical connectivity, we assume that such results could be transposed to connectivity loss. The time required to establish an equilibrium between spatial connectivity and species richness or diversity is longer at larger spatial and biological scales compared to smaller scales (O’Neill et al. 1986; Allen and Starr 1988); thus, the relaxation time of plant assemblages occurs at different spatial scales.

To our knowledge, only Naaf and Kolk (2015) and Haddad et al. (2015) have investigated how connectivity affects the magnitude of immigration credit. By studying newlyestablished forest patches, Naaf and Kolk (2015) found that the magnitude of immigration credit mainly depends on the structural connectivity of forests (IFM index). In connected forest patches, immigration lag affected five forest specialist species compared to nine species in highly isolated forest patches. Haddad et al. (2015) obtained similar results by studying successional vegetation of pine plantations over a decade in the Savannah River Site experimental design (Box 2). More specifically, immigration lags resulted in $15 \%$ fewer species after a decade in unconnected patches compared to connected patches. Future studies should investigate this effect in other community types.

\section{Dispersal traits promoting time-dependent responses to connectivity}

Because plants might respond to connectivity time-dependently (either with relaxation time or with immigration credit), some biological traits might promote such effects. For instance, the life duration of species or seed-bank persistence might contribute to the delayed response to changes in connectivity. The work of Lindborg (2007) supported this assumption, demonstrating that the proportion of short-lived plant species is influenced by current structural connectivity, whereas that of clonal long-lived and long seed-bank persistence species is influenced by historical structural connectivity (Table 1). Conversely, some traits might influence the effect of immigration lag. For instance, species with poor dispersal abilities might 
contribute strongly to immigration credit. This assumption was verified by Naaf and Kolk

556 (2015). The authors demonstrated that immigration credit is higher in species that are characterised by low seed production and dispersal potential (sensu Vittoz and Engler 2007) compared to species with high seed production and dispersal potential in forest specialist communities. However, few studies have used trait-based approaches to determine how connectivity changes over time.

\section{Effect of landscape connectivity on actual seed dispersal}

563 Studies assessing actual dispersal (Fig. 1) in response to connectivity have developed over the 564 last 15 years, but remain limited. Many papers have assessed seed fluxes at the community 565 level, particularly for water-dispersed species (e.g. Andersson and Nilsson 2002; Boedeltje et 566 al. 2003, 2004; Moggridge et al. 2009), but very few studies have considered the effect of connectivity on these seed fluxes. Only a few studies have taken connectivity into account, with the response of plants being almost exclusively assessed at the species level, which are presented in the next section.

Number of dispersed seeds

572 The effect of connectivity on the abundance of dispersed seeds has mostly been investigated 573 under experimental conditions, focusing on particular species that were selected for their 574 abundance or representativeness of the community process. Seed fluxes for three plant species 575 dispersed by birds were assessed in connected and unconnected patches using the Savannah 576 River Site experimental design. Seeds were trapped in peripheral (i.e. receiver) patches, of 577 which just one was connected to the central patch and the others were not (Box 2). To provide 578 confidence that all seeds or fruits found in seed traps were exclusively derived from the central patch, two methods were carried out, depending on the abundance of the species considered: i) 
the removal of all naturally occurring individuals from the peripheral patches, and ii) the use of marked seeds or fruits in the central patch by fluorescence. Based on this approach, Tewksbury et al. (2002) reported that twice the number of Ilex vomitaria seeds was trapped in connected patches compared to unconnected patches. The authors also reported that a greater proportion (an increase of 18\%) of Myrica cerifera were present in faecal samples collected in connected patches that contained fluorescent powder compared to unconnected patches. Similar results were obtained by Haddad et al. (2003) for both Myrica cerifera and Rhus copallina, with five and two times more seeds, respectively, being transported from the central patch in connected compared to unconnected patches. Using an individual-based model, Levey et al. (2005) demonstrated that the distribution of Myrica cerifera is explained by the movement of birds that were $31 \%$ more likely to be found in connected patches compared to unconnected patches.

591 Thus, it is important that future studies extend these analyses to consider other modes of dispersal.

\section{Seed flux composition}

595 Studies analysing the seed communities of plants that actually disperse in response to landscape 596 connectivity remain scarce. To our knowledge, only one study investigated this type of 597 relationship (Suárez-Esteban et al. 2013). The authors assumed that unpaved roads act as 598 corridors, and analysed actual dispersal along unpaved roads in comparison to adjacent 599 scrubland, which was not considered to be a corridor. By analysing the seeds of all fleshy-fruit 600 shrubs that were contained in the faecal samples of frugivorous mammals, the authors 601 demonstrated that the composition of seed communities in unpaved roads differed to that 602 observed in scrublands, due to the effect of corridors on animal behaviour. However, this 603 finding was dependent on the animal-vector being considered (rabbit, carnivore or ungulate). 
604 Such studies analysing actual dispersal are expected to improve the accuracy of assessing current seed dispersal, allowing us to determine how connectivity influences dispersal per se.

606

\section{New prospects for future research}

608 Analysing the response of the plant community to connectivity loss has not been as extensively

609 studied as for animal guilds, despite the dispersal specificity of plants. Through our review, we 610 demonstrated that: i) landscape connectivity does promote the actual dispersal of plants 611 between communities (section 4), but ii) its influence on community taxonomic structure does 612 not follow a general pattern due to the many factors that modulate its effect (sections 1 and 613 3). We also found that: iii) the use of functional traits provides a better understanding of the 614 mechanisms involved in plant responses to connectivity (sections 2 and 3).

615 These three key-findings should be considered in light of several limitations related to 616 the studies selected for this review. First, this review did not compare the relative role of 617 landscape connectivity vs. other landscape factors (e.g. habitat size or habitat amount) in 618 structuring plant communities. Thus, it is beyond the scope of this review to shed light on the 619 SLOSS (Single Large Or Several Small) debate, derived from island biogeography or to discuss 620 on the relative importance between SLOSS and the Habitat Amount Hypothesis (Fahrig 2013) 621 (but see Lindgren and Cousins 2017). Secondly, the dark diversity (i.e. all species that are 622 absent from a habitat patch but that could disperse to and establish there, Pärtel et al. 2011) may 623 result from dispersal limitation (Riibak et al. 2015). However, the reviewed studies investigated 624 the role of landscape connectivity on expressed plant communities (i.e. potential dispersal, Fig. 625 1), rather than on the absence of species, neglecting the role of landscape connectivity on dark 626 diversity. Third, the consideration of traits in the response to connectivity raises a question for 627 some authors (see for example Haddad et al. 2015). These authors suggest that plant dispersal 628 might be better described by statistical probabilities and stochastic factors rather than traits. 
629 Within these limitations, we identified research prospects from the three key-findings identified 630 here:

632 1) Landscape connectivity promotes actual dispersal between connected communities. Because 633 of the scarcity and the animal-dispersed species focus of the studies on this topic, we can only 634 encourage more studies to use this approach, particularly for other dispersal modes.

2) The influence of landscape connectivity on plant taxonomic structure do not follow a general pattern because of the multiplicity of factors that modulate its effect. To better disentangle the effect of landscape connectivity from the other factors, explicit consideration of both spatial and temporal scales is necessary to define a relevant resolution of the landscape. An assessment

640 of landscape connectivity at different spatial scales should be developed to detect the dispersal range at which plant species respond to changes in connectivity. Because some species exhibit

642 a time lag in their response to connectivity changes, efforts to incorporate historical data to 643 model historical connectivity are necessary. In addition, the presence of a corridor per se is not 644 sufficient to connect habitats. Indeed, the quality of the corridors (or landscape elements) should 645 be considered and determined by their management practice. For instance, in hedgerows, the 646 corridor quality is determined by the vegetation structure and vertical organisation at a fine 647 scale. The assessment of connectivity might account for these fine-scale characteristics by using 648 recent remote sensing techniques (Betbeder et al. 2014) to better predict species abundance 649 such as for carabids (Betbeder et al. 2015). Future studies should investigate this new 650 methodology for plants. Connectivity might be evaluated while considering the potential 651 interaction between habitats, to better account for the degree of ecological specialisation of 652 species. Complementarity between the different ecological corridor types (i.e. provided by 653 different habitat types) might explain the lowest sensitivity of generalist species to connectivity 
654 loss. In contrast, antagonistic effects might occur for specialist species. The deployment of such 655 multi-habitat landscape connectivity models (which independently consider different 656 ecological corridor types) could enhance our understanding of the responses of plant species to 657 connectivity at a community scale.

658

659 3) Using functional traits provides a better understanding of the mechanisms involved in plant 660 responses to connectivity. Some trait syndromes characterise species that are highly sensitive 661 to connectivity loss. Determining trait combinations that might predict, at best, plant responses 662 in time and space to changes in connectivity is a key challenge of forthcoming research. Using 663 such functional indicators would allow these species to be detected in a manner that is 664 reproducible and independent of ecosystems and regional pools (Lavorel et al. 1997). This 665 approach is promising for defining general functional indicators of sensitivity. Such indicators 666 may, for instance, help to identify species that are less likely to colonise and establish in patches 667 after connectivity loss. In addition, the use of functional connectivity indices, which considers 668 the dispersal distance of species, should be generalized in studies investigating plants, 669 especially at the community level. The dispersal traits that promote time-dependent responses 670 to connectivity that we have identified should be integrated in these indices to provide an 671 adequate understanding of connections between plant communities over time.

672

673 Beyond highlighting needs for future research, this synthesis provides information of use for 674 land-use planning (green and blue infrastructure implementation, for instance, Sandström 2002; 675 Tzoulas et al. 2007). Such information could provide new methods and decision-making tools 676 to promote the operational establishment of ecological corridors, taking plant communities into 677 account. 


\section{Acknowledgements}

680 This work was funded by the Fondation de France (BISCO project). We thank the two 681 anonymous referees for their constructive work and remarks on the manuscript. 
682

683

684

685

686

687

688

689

690

691

692

693

694

695

696

697

698

699

700

701

702

703

704

705

706

707

708

709

710

711

712

713

714

715

\section{References}

Aavik T, Holderegger R, Bolliger J (2014) The structural and functional connectivity of the grassland plant Lychnis flos-cuculi. Heredity 112:471-478. doi: 10.1038/hdy.2013.120

Adriaens D, Honnay O, Hermy M (2006) No evidence of a plant extinction debt in highly fragmented calcareous grasslands in Belgium. Biol Conserv 133:212-224. doi: 10.1016/j.biocon.2006.06.006

Adriaensen F, Chardon JP, De Blust G, Swinnen E, Villalba S, Gulinck H, Matthysen E (2003) The application of 'leastcost' modelling as a functional landscape model. Landsc Urban Plan 64:233-247. https://doi.org/10.1016/S0169-2046(02)00242-6

Allen TFH, Starr TB (1988) Hierarchy: Perspectives for Ecological Complexity. University of Chicago Press, Chicago

Andersson E, Nilsson C (2002) Temporal variation in the drift of plant litter and propagules in a small boreal river. Freshw Biol 47:1674-1684. doi: 10.1046/j.1365-2427.2002.00925.x

Andreasen C, Stryhn H, Streibig JC (1996) Decline of the Flora in Danish Arable Fields. J Appl Ecol 33:619-626. doi: 10.2307/2404990

Archer S, Pyke DA (1991) Plant-animal interactions affecting plant establishment and persistence on revegetated rangeland. J Range Manag 44:558-565. doi: 10.2307/4003036 Arellano-Rivas A, De-Nova JA, Munguía-Rosas MA (2016) Patch isolation and shape predict plant functional diversity in a naturally fragmented forest. J Plant Ecol 1-11. doi: 10.1093/jpe/rtw119

Auffret AG, Rico Y, Bullock JM, Hooftman DAP, Pakeman RJ, Soons MB, Suárez-Esteban A, Traveset A, Wagner H, Cousins SAO (2017) Plant functional connectivity - integrating landscape structure and effective dispersal. J Ecol. doi: 10.1111/1365-2745.12742

Ayram CAC, Mendoza ME, Etter A, Salicrup DRP (2016) Habitat connectivity in biodiversity conservation: A review of recent studies and applications. Prog Phys Geogr Earth Environ 40:7-37. doi: 10.1177/0309133315598713

Baessler C, Klotz S (2006) Effects of changes in agricultural land-use on landscape structure and arable weed vegetation over the last 50 years. Agric Ecosyst Environ 115:43-50. doi: 10.1016/j.agee.2005.12.007

Beier P, Noss RF (1998) Do Habitat Corridors Provide Connectivity? Conserv Biol 12:12411252. doi: 10.1111/j.1523-1739.1998.98036.x

Bennett AF (2003) Linkages in the Landscape: The Role of Corridors and Connectivity in Wildlife Conservation. IUCN-The World Conservation Union, Gland, Cambridge 
716 Bennett AJ, Radford JQ, Haslem A (2006) Properties of Land Mosaics: Implications for Nature

717 Conservation in Agricultural Environments. Biol Conserv 133:250-264. doi:

$718 \quad 10.1016 /$ j.biocon.2006.06.008

719 Betbeder J, Hubert-Moy L, Burel F, Corgne S, Baudry J (2015) Assessing ecological habitat

720 structure from local to landscape scales using synthetic aperture radar. Ecol Indic 52:545-557.

721 doi: 10.1016/j.ecolind.2014.11.009

722 Betbeder J, Nabucet J, Pottier E, Baudry J, Corgne S, Hubert-Moy L (2014) Detection and 723 Characterization of Hedgerows Using TerraSAR-X Imagery. Remote Sens 6:3752-3769. doi: $724 \quad 10.3390 /$ rs6053752

725 Boedeltje G, Bakker JP, Bekker RM, Van Groenendael JM, Soesbergen M (2003) Plant 726 dispersal in a lowland stream in relation to occurrence and three specific life-history traits of 727 the species in the species pool. J Ecol 91:855-866. doi: 10.1046/j.1365-2745.2003.00820.x

728 Boedeltje G, Bakker JP, Ten Brinke A, Van Groenendael JM, Soesbergen M (2004) Dispersal 729 phenology of hydrochorous plants in relation to discharge, seed release time and buoyancy of 730 seeds: the flood pulse concept supported. J Ecol 92:786-796. doi: 10.1111/j.0022$731 \quad 0477.2004 .00906 . x$

732 Bornette G, Amoros C, Lamouroux N (1998) Aquatic plant diversity in riverine wetlands: the 733 role of connectivity. Freshw Biol 39:267-283. doi: 10.1046/j.1365-2427.1998.00273.x

734 Bowne DR, Bowers MA (2004) Interpatch movements in spatially structured populations: a 735 literature review. Landsc Ecol 19:1-20. doi: 10.1023/B:LAND.0000018357.45262.b9

736 Brückmann SV, Krauss J, Steffan-Dewenter I (2010) Butterfly and plant specialists suffer from 737 reduced connectivity in fragmented landscapes. J Appl Ecol 47:799-809. doi: 10.1111/j.1365$738 \quad 2664.2010 .01828 . x$

739 Brudvig LA (2016) Interpreting the effects of landscape connectivity on community diversity. 740 J Veg Sci 27:4-5. doi: 10.1111/jvs.12365

741 Brudvig LA, Damschen EI, Tewksbury JJ, Haddad NM, Levey DJ (2009) Landscape 742 connectivity promotes plant biodiversity spillover into non-target habitats. Proc Natl Acad Sci 743 106:9328-9332. doi: 10.1073/pnas.0809658106

744 Burel F, Baudry J (1999) Ecologie du paysage. Concepts, méthodes et applications. Editions 745 TEC et DOC, Paris

746 Calabrese JM, Fagan WF (2004) A comparison-shopper's guide to connectivity metrics. Front 747 Ecol Environ 2:529-536. doi: 10.1890/1540-9295(2004)002[0529:ACGTCM]2.0.CO;2 
748 Chetkiewicz C-LB, Clair CCS, Boyce MS (2006) Corridors for Conservation: Integrating 749 Pattern and Process. Annu Rev Ecol Evol Syst 37:317-342. doi:

750 10.1146/annurev.ecolsys.37.091305.110050

751 Cornelissen JHC, Lavorel S, Garnier E, Díaz S, Buchmann N, Gurvich DE, Reich PB, Ter 752 Steege H, Morgan HD, Van Der Heijden MGA, Pausas JG, Poorter H (2003) A handbook of 753 protocols for standardised and easy measurement of plant functional traits worldwide. Aust $\mathbf{J}$ 754 Bot 51:335-380. doi: 10.1071/BT02124

755 Cousins SAO, Ohlson H, Eriksson O (2007) Effects of historical and present fragmentation on 756 plant species diversity in semi-natural grasslands in Swedish rural landscapes. Landsc Ecol 757 22:723-730. doi: 10.1007/s10980-006-9067-1

758 Cousins SAO, Vanhoenacker D (2011) Detection of extinction debt depends on scale and 759 specialisation. Biol Conserv 144:782-787. doi: 10.1016/j.biocon.2010.11.009

760 Damschen EI, Baker DV, Bohrer G, Nathan R, Orrock JL, Turner JR, Brudvig LA, Haddad 761 NM, Levey DJ, Tewksbury JJ (2014) How fragmentation and corridors affect wind dynamics 762 and seed dispersal in open habitats. Proc Natl Acad Sci 111:3484-3489. doi: 763 10.1073/pnas.1308968111

764 Damschen EI, Brudvig LA, Haddad NM, Levey DJ, Orrock JL, Tewksbury JJ (2008) The 765 movement ecology and dynamics of plant communities in fragmented landscapes. Proc Natl 766 Acad Sci 105:19078-19083. doi: 10.1073/pnas.0802037105

767 Damschen EI, Haddad NM, Orrock JL, Tewksbury JJ, Levey DJ (2006) Corridors increase 768 plant species richness at large scales. Science 313:1284-1286. doi: 10.1126/science.1130098

769 De Ryck DJR, Robert EMR, Schmitz N, Van der Stocken T, Di Nitto D, Dahdouh-Guebas F, 770 Koedam N (2012) Size does matter, but not only size: Two alternative dispersal strategies for 771 viviparous mangrove propagules. Aquat Bot 103:66-73. doi: 10.1016/j.aquabot.2012.06.005

772 Diamond JM (1972) Biogeographic kinetics: estimation of relaxation times for avifaunas of 773 southwest pacific islands. Proc Natl Acad Sci 69:3199-3203. doi: 10.1073/pnas.69.11.3199

774 Dzwonko Z, Loster S (1988) Species richness of small woodlands on the western Carpathian 775 foothills. Vegetatio 76:15-27. doi: 10.1007/BF00047384

776 Eriksson O (1996) Regional Dynamics of Plants: A Review of Evidence for Remnant, Source777 Sink and Metapopulations. Oikos 77:248-258. doi: 10.2307/3546063

778 Evju M, Blumentrath S, Skarpaas O, Stabbetorp OE (2015) Plant species occurrence in a 779 fragmented grassland landscape: the importance of species traits. Biodivers Conserv 24:547780 561. doi: 10.1007/s10531-014-0835-y 
781 Fahrig, L. (2013). Rethinking patch size and isolation effects: the habitat amount hypothesis.

782 Journal of Biogeography, 40(9), 1649-1663. doi:10.1111/jbi.12130

783 Fahrig L (2003) Effects of Habitat Fragmentation on Biodiversity. Annu Rev Ecol Evol Syst

784

785

786

787

788

789

790

791

792

793

794

795

796

797

798

799

800

801

802

803

804

805

806

807

808

812

809 Gignac LD, Dale MRT (2007) Effects of size, shape, and edge on vegetation in remnants of the 810 upland boreal mixed-wood forest in agro-environments of Alberta, Canada. Can J Bot 85:273811 284. doi: 10.1139/B07-018 813 effectiveness. Conserv Biol 24:660-668. doi: 10.1111/j.1523-1739.2010.01450.x 34:487-515. doi: 10.1146/annurev.ecolsys.34.011802.132419

Fahrig L, Merriam G (1985) Habitat Patch Connectivity and Population Survival. Ecology 66:1762-1768. doi: 10.2307/2937372

Favre-Bac L, Ernoult A, Mony C, Rantier Y, Nabucet J, Burel F (2014) Connectivity and propagule sources composition drive ditch plant metacommunity structure. Acta Oecologica 61:57-64. doi: 10.1016/j.actao.2014.10.006

Favre-Bac L, Lamberti-Raverot B, Puijalon S, Ernoult A, Burel F, Guillard L, Mony C (2017a) Plant dispersal traits determine hydrochorous species tolerance to connectivity loss at the landscape scale. J Veg Sci 28:605-615. doi: 10.1111/jvs.12518

Favre-Bac L, Mony C, Burel F, Seimandi-Corda G, Ernoult A (2017b) Connectivity drives the functional diversity of plant dispersal traits in agricultural landscapes: the example of ditch metacommunities. Landsc Ecol 32:2029-2040. doi: 10.1007/s10980-017-0564-1

Fischer J, Lindenmayer DB (2007) Landscape modification and habitat fragmentation: a synthesis. Glob Ecol Biogeogr 16:265-280. doi: 10.1111/j.1466-8238.2007.00287.x

Fletcher RJ, Burrell NS, Reichert BE, Vasudev D, Austin JD (2016) Divergent Perspectives on Landscape Connectivity Reveal Consistent Effects from Genes to Communities. Curr Landsc Ecol Rep 1:67-79. doi: 10.1007/s40823-016-0009-6

Fukami T (2015) Historical Contingency in Community Assembly: Integrating Niches, Species Pools, and Priority Effects. Annu Rev Ecol Evol Syst 46:1-23. doi: 10.1146/annurev-ecolsys110411-160340

Fukami T, Nakajima M (2013) Complex plant-soil interactions enhance plant species diversity by delaying community convergence. J Ecol 101:316-324. doi: 10.1111/1365-2745.12048

García-Feced C, Saura S, Elena-Rosselló R (2011) Improving landscape connectivity in forest districts: A two-stage process for prioritizing agricultural patches for reforestation. For Ecol Manag 261:154-161. doi: 10.1016/j.foreco.2010.09.047

12 Gilbert-Norton L, Wilson R, Stevens JR, Beard KH (2010) A meta-analytic review of corridor 
814 Godefroid S, Koedam N (2003) How important are large vs. small forest remnants for the 815 conservation of the woodland flora in an urban context? Glob Ecol Biogeogr 12:287-298. doi: 816 10.1046/j.1466-822X.2003.00035.x

817 Grime JP (2006) Trait convergence and trait divergence in herbaceous plant communities: 818 Mechanisms and consequences. J Veg Sci 17:255-260. doi: 10.1111/j.1654819 1103.2006.tb02444.x

820 Groves CR, Jensen DB, Valutis LL, Redford KH, Shaffer ML, Scott JM, Baumgartner JV, 821 Higgins JV, Beck MW, Anderson MG (2002) Planning for Biodiversity Conservation: Putting 822 Conservation Science into Practice. A seven-step framework for developing regional plans to conserve biological diversity, based upon principles of conservation biology and ecology, is 824 being used extensively by the nature conservancy to identify priority areas for conservation. 825 BioScience 52:499-512. doi: 10.1641/0006-3568(2002)052[0499:PFBCPC]2.0.CO;2

826 Guisan A, Thuiller W (2005) Predicting species distribution: offering more than simple habitat 827 models. Ecol Lett 8:993-1009. doi: 10.1111/j.1461-0248.2005.00792.x

828 Haddad NM, Bowne DR, Cunningham A, Levey DJ, Sargent S, Spira T (2003) Corridor use by 829 diverse taxa. Ecology 84:609-615. doi: 10.1890/0012-9658(2003)084[0609:CUBDT]2.0.CO;2 830 Haddad NM, Brudvig LA, Clobert J, Davies KF, Gonzalez A, Holt RD, Lovejoy TE, Sexton 831 JO, Austin MP, Collins CD, Cook WM, Damschen EI, Ewers RM, Foster BL, Jenkins CN, 832 King AJ, Laurance WF, Levey DJ, Margules CR, Melbourne BA, Nicholls AO, Orrock JL, Son 833 D-X, Townshend JR (2015) Habitat fragmentation and its lasting impact on Earth's ecosystems. 834 Sci Adv 1:e1500052. doi: 10.1126/sciadv.1500052

835 Haddad NM, Hudgens B, Damschen EI, Levey DJ, Orrock JL, Tewksbury JJ, Weldon AJ 836 (2011) Assessing positive and negative ecological effects of corridors. In: Liu J, Hull V, 837 Morzillo AT, Wiens JA (eds) Sources, Sinks and Sustainability. Cambridge University Press, 838 Cambridge, pp 475-503

839 Haddad NM, Tewksbury JJ (2006) Impacts of corridors on populations and communities. In: 840 Crooks KR, Sanjayan M (eds) Connectivity Conservation: maintaining connections for nature. 841 Cambridge University Press, Cambridge, pp 390-415

842 Hanski I (1994) A Practical Model of Metapopulation Dynamics. J Anim Ecol 63:151-162. 843 doi: $10.2307 / 5591$

844 Helm A, Hanski I, Pärtel M (2006) Slow response of plant species richness to habitat loss and 845 fragmentation. Ecol Lett 9:72-77. doi: 10.1111/j.1461-0248.2005.00841.x 
846 Herben T, Goldberg DE (2014) Community assembly by limiting similarity vs. competitive

847 hierarchies: testing the consequences of dispersion of individual traits. J Ecol 102:156-166. 848 doi: $10.1111 / 1365-2745.12181$

849 Higgins SI, Nathan R, Cain ML (2003) Are Long-Distance Dispersal Events in Plants Usually 850 Caused by Nonstandard Means of Dispersal? Ecology 84:1945-1956. doi: 10.1890/01-0616

851 Honnay O, Hermy M, Coppin P (1999) Effects of area, age and diversity of forest patches in 852 Belgium on plant species richness, and implications for conservation and reforestation. Biol 853 Conserv 87:73-84. doi: 10.1016/S0006-3207(98)00038-X

854 Jackson ST, Sax DF (2010) Balancing biodiversity in a changing environment: extinction debt, 855 immigration credit and species turnover. Trends Ecol Evol 25:153-160. doi: $856 \quad 10.1016 /$ j.tree.2009.10.001

857 Johst K, Brandl R, Eber S (2002) Metapopulation persistence in dynamic landscapes: the role 858 of dispersal distance. Oikos 98:263-270. doi: 10.1034/j.1600-0706.2002.980208.x

859 Katoh K, Sakai S, Takahashi T (2009) Factors maintaining species diversity in satoyama, a 860 traditional agricultural landscape of Japan. Biol Conserv 142:1930-1936. doi: $861 \quad 10.1016 /$ j.biocon.2009.02.030

862 Kleijn D, Kohler F, Báldi A, Concepción ED, Clough Y, Díaz M, Gabriel D, Holzschuh A, 863 Knop E, Kovács A, Marshall EJP, Tscharntke T, Verhulst J (2009) On the relationship between 864 farmland biodiversity and land-use intensity in Europe. Proc Biol Sci 276:903-909. doi: $865 \quad 10.1098 / \mathrm{rspb} .2008 .1509$

866 Kleijn D, Verbeek M (2000) Factors affecting the species composition of arable field boundary 867 vegetation. J Appl Ecol 37:256-266. doi: 10.1046/j.1365-2664.2000.00486.x

868 Koen EL, Bowman J, Walpole AA (2012) The effect of cost surface parameterization on 869 landscape resistance estimates. Mol Ecol Resour 12:686-696. doi: 10.1111/j.1755870 0998.2012.03123.x

871 Kolb A, Diekmann M (2005) Effects of Life-History Traits on Responses of Plant Species to 872 Forest Fragmentation. Conserv Biol 19:929-938. doi: 10.1111/j.1523-1739.2005.00065.X

873 Kuussaari M, Bommarco R, Heikkinen RK, Helm A, Krauss J, Lindborg R, Öckinger E, Pärter 874 M, Pino J, Rodà F, Stefanescu C, Teder T, Zobel M, Steffan-Dewenter I (2009) Extinction debt: 875 a challenge for biodiversity conservation. Trends Ecol Evol 24:564-571. doi: $876 \quad 10.1016 /$ j.tree.2009.04.011

877 Lavorel S, McIntyre S, Landsberg J, Forbes TDA (1997) Plant functional classifications: from 878 general groups to specific groups based on response to disturbance. Trends Ecol Evol 12:474879 478. doi: 10.1016/S0169-5347(97)01219-6 
880 Leibold MA, Holyoak M, Mouquet N, Amarasekare P, Chase JM, Hoopes MF, Holt RD, Shurin

881 JB, Law R, Tilman D, Loreau M, Gonzalez A (2004) The metacommunity concept: a 882 framework for multi-scale community ecology. Ecol Lett 7:601-613. doi: 10.1111/j.1461883 0248.2004.00608.x

884 Levey DJ, Bolker BM, Tewksbury JJ, Sargent S, Haddad NM (2005) Effects of landscape 885 corridors on seed dispersal by birds. Science 309:146-148. doi: 10.1126/science.1111479

886 Lindborg R (2007) Evaluating the distribution of plant life-history traits in relation to current 887 and historical landscape configurations. J Ecol 95:555-564. doi: 10.1111/j.1365$888 \quad 2745.2007 .01232 . x$

889 Lindborg R, Eriksson O (2004) Historical Landscape Connectivity Affects Present Plant 890 Species Diversity. Ecology 85:1840-1845. doi: 10.1890/04-0367

891 Lindgren JP, Cousins SAO (2017) Island biogeography theory outweighs habitat amount 892 hypothesis in predicting plant species richness in small grassland remnants. Landsc Ecol 893 32:1895-1906. doi: 10.1007/s10980-017-0544-5

894 Logue JB, Mouquet N, Peter H, Hillebrand H (2011) Empirical approaches to 895 metacommunities: a review and comparison with theory. Trends Ecol Evol 26:482-491. doi: 896 10.1016/j.tree.2011.04.009

897 Luoto M, Rekolainen S, Aakkula J, Pykälä J (2003) Loss of Plant Species Richness and Habitat 898 Connectivity in Grasslands Associated with Agricultural Change in Finland. AMBIO J Hum 899 Environ 32:447-452. doi: 10.1579/0044-7447-32.7.447

900 MacArthur R, Levins R (1967) The Limiting Similarity, Convergence, and Divergence of 901 Coexisting Species. Am Nat 101:377-385. doi: 10.1086/282505

902 MacArthur RH, Wilson E (1967) The Theory of Island Biogeography. Princeton University 903 Press, Princeton

904 McRae BH, Dickson BG, Keitt TH, Shah VB (2008) Using Circuit Theory to Model 905 Connectivity in Ecology, Evolution, and Conservation. Ecology 89:2712-2724. doi: $906 \quad 10.1890 / 07-1861.1$

907 Minor ES, Gardner RH (2011) Landscape connectivity and seed dispersal characteristics inform 908 the best management strategy for exotic plants. Ecol Appl Publ Ecol Soc Am 21:739-749

909 Minor ES, Tessel SM, Engelhardt KAM, Lookingbill TR (2009) The role of landscape 910 connectivity in assembling exotic plant communities: a network analysis. Ecology 90:1802911 1809. doi: 10.1890/08-1015.1 
912 Moggridge HL, Gurnell AM, Mountford JO (2009) Propagule input, transport and deposition

913 in riparian environments: the importance of connectivity for diversity. J Veg Sci 20:465-474.

914 doi: 10.1111/j.1654-1103.2009.05498.x

915 Moilanen A, Nieminen M (2002) Simple Connectivity Measures in Spatial Ecology. Ecology 916 83:1131-1145. doi: 10.2307/3071919

917 Morato RG, Ferraz KMPM de B, de Paula RC, de Campos CB (2014) Identification of Priority

918 Conservation Areas and Potential Corridors for Jaguars in the Caatinga Biome, Brazil. PLoS

919 ONE 9:. doi: 10.1371/journal.pone.0092950

920 Mouchet MA, Villéger S, Mason NWH, Mouillot D (2010) Functional diversity measures: an 921 overview of their redundancy and their ability to discriminate community assembly rules. Funct 922 Ecol 24:867-876. doi: 10.1111/j.1365-2435.2010.01695.x

923 Mouquet N, E. Miller T, Daufresne T, M. Kneitel J (2006) Consequences of varying regional 924 heterogeneity in source-sink metacommunities. Oikos 113:481-488. doi: 10.1111/j.2006.0030$925 \quad 1299.14582 . \mathrm{x}$

926 Mouquet N, Loreau M (2003) Community patterns in source-sink metacommunities. Am Nat $927 \quad 162: 544-557$

928 Murphy HT, Lovett-Doust J (2004) Context and connectivity in plant metapopulations and 929 landscape mosaics: does the matrix matter? Oikos 105:3-14. doi: 10.1111/j.0030930 1299.2004.12754.X

931 Naaf T, Kolk J (2015) Colonization credit of post-agricultural forest patches in NE Germany 932 remains 130-230years after reforestation. Biol Conserv 182:155-163. doi: 933 10.1016/j.biocon.2014.12.002

934 Nathan R (2006) Long-distance dispersal of plants. Science 313:786-788. doi: $935 \quad 10.1126 /$ science. 1124975

936 Nathan R, Katul GG, Horn HS, Thomas SM, Oren R, Avissar R, Pacala SW, Levin SA (2002)

937 Mechanisms of long-distance dispersal of seeds by wind. Nature 418:409-413. doi: $938 \quad 10.1038 /$ nature00844

939 Nilsson C, Brown RL, Jansson R, Merritt DM (2010) The role of hydrochory in structuring 940 riparian and wetland vegetation. Biol Rev Camb Philos Soc 85:837-858. doi: 10.1111/j.1469941 185X.2010.00129.x

942 O’Neill RV, Deangelis DL, Waide JB, Allen TFH (1986) A Hierarchical Concept of 943 Ecosystems. Princeton University Press, Princeton

944 Orrock JL, Damschen EI (2005) Corridors Cause Differential Seed Predation. Ecol Appl 945 15:793-798. doi: 10.1890/04-1129 
946 Orrock JL, Danielson BJ, Burns MJ, Levey DJ (2003) Spatial Ecology of Predator-Prey

947 Interactions: Corridors and Patch Shape Influence Seed Predation. Ecology 84:2589-2599. doi:

$948 \quad 10.1890 / 02-0439$

949 Ovaskainen O, Hanski I (2002) Transient Dynamics in Metapopulation Response to 950 Perturbation. Theor Popul Biol 61:285-295. doi: 10.1006/tpbi.2002.1586

951 Pacala SW, Tilman D (1994) Limiting similarity in mechanistic and spatial models of plant 952 competition in heterogeneous environments. Am Nat 143:222-257. doi: 10.1086/285602

953 Pärtel M, Szava-Kovats R, Zobel M (2011) Dark diversity: shedding light on absent species. 954 Trends Ecol Evol 26:124-128. doi: 10.1016/j.tree.2010.12.004

955 Pascual-Hortal L, Saura S (2006) Comparison and development of new graph-based landscape 956 connectivity indices: towards the priorization of habitat patches and corridors for conservation. 957 Landsc Ecol 21:959-967. doi: 10.1007/s10980-006-0013-z

958 Patterson BD, Atmar W (1986) Nested subsets and the structure of insular mammalian faunas 959 and archipelagos. Biol J Linn Soc 96:65-82. doi: 10.1007/BF00317508

960 Piessens K, Honnay O, Hermy M (2005) The role of fragment area and isolation in the 961 conservation of heathland species. Biol Conserv 122:61-69. doi: 10.1016/j.biocon.2004.05.023 962 Piessens K, Honnay O, Nackaerts K, Hermy M (2004) Plant Species Richness and Composition 963 of Heathland Relics in North-Western Belgium: Evidence for a Rescue-Effect? J Biogeogr 964 31:1683-1692. doi: 10.2307/3554767

965 Pollux BJA, Luteijn A, Van Groenendael JM, Ouborg NJ (2009) Gene flow and genetic 966 structure of the aquatic macrophyte Sparganium emersum in a linear unidirectional river. 967 Freshw Biol 54:64-76. doi: 10.1111/j.1365-2427.2008.02100.x

968 Pyke DA, Archer S (1991) Plant-plant interactions affecting plant establishment and persistence 969 on revegetated rangeland. J Range Manag 44:550-557. doi: 10.2307/4003036

970 Rayfield B, Fortin M-J, Fall A (2010) The sensitivity of least-cost habitat graphs to relative cost 971 surface values. Landsc Ecol 25:519-532. doi: 10.1007/s10980-009-9436-7

972 Riibak K, Reitalu T, Tamme R, Helm A, Gerhold P, Znamenskiy S, Bengtsson K, Rosén E, 973 Prentice HC, Pärtel M (2015) Dark diversity in dry calcareous grasslands is determined by 974 dispersal ability and stress-tolerance. Ecography 38:713-721. doi: 10.1111/ecog.01312

975 Rossetti MR, Tscharntke T, Aguilar R, Batáry P (2017) Responses of insect herbivores and 976 herbivory to habitat fragmentation: a hierarchical meta-analysis. Ecol Lett 20:264-272. doi: 977 10.1111/ele.12723

978 Sandström UG (2002) Green Infrastructure Planning in Urban Sweden. Plan Pract Res 17:373979 385. doi: 10.1080/02697450216356 
980 Saura S, Pascual-Hortal L (2007) A new habitat availability index to integrate connectivity in 981 landscape conservation planning: Comparison with existing indices and application to a case

982

983

984

985

986

987

988

989

990

991

992

993

994

995

996

997

998

999

1000

1001

1002

1003

1004

1005

1006

1007

1008

1009

1010

1011

study. Landsc Urban Plan 83:91-103. doi: 10.1016/j.landurbplan.2007.03.005

Scanlan M (1981) Biogeography of forest plants in the Prairie-Forest Ecotone in Western Minnesota. In: Burges RL, Sharpe DM (eds) Forest Island Dynamics in Man-dominated Landscapes. Springer, Berlin, pp 97-124

Schleicher A, Biedermann R, Kleyer M (2011) Dispersal traits determine plant response to habitat connectivity in an urban landscape. Landsc Ecol 26:529-540. doi: 10.1007/s10980-0119579-1

Simberloff D, Cox J (1987) Consequences and Costs of Conservation Corridors. Conserv Biol 1:63-71. doi: 10.1111/j.1523-1739.1987.tb00010.x

Soomers H, Winkel DN, Du Y, Wassen MJ (2010) The dispersal and deposition of hydrochorous plant seeds in drainage ditches. Freshw Biol 55:2032-2046. doi: 10.1111/j.13652427.2010.02460.x

Sorensen AE (1986) Seed Dispersal by Adhesion. Annu Rev Ecol Syst 17:443-463. doi: 10.1146/annurev.es.17.110186.002303

Spear SF, Balkenhol N, Fortin M-J, McRae BH, Scribner K (2010) Use of resistance surfaces for landscape genetic studies: considerations for parameterization and analysis. Mol Ecol 19:3576-3591. doi: 10.1111/j.1365-294X.2010.04657.x

Stoate C, Boatman N, Borralho R, Carvalho CR, de Snoo GR, Eden P (2001) Ecological impacts of arable intensification in Europe. J Environ Manage 63:337-365. doi: 10.1006/jema.2001.0473

Stöcklin J, Winkler E (2004) Optimum reproduction and dispersal strategies of a clonal plant in a metapopulation: a simulation study with Hieracium pilosella. Evol Ecol 18:563-584. doi: 10.1007/s10682-004-5144-6

Suárez-Esteban A, Delibes M, Fedriani JM (2013) Barriers or corridors? The overlooked role of unpaved roads in endozoochorous seed dispersal. J Appl Ecol 50:767-774. doi: 10.1111/1365-2664.12080

Sullivan LL, Johnson BL, Brudvig LA, Haddad NM (2011) Can dispersal mode predict corridor effects on plant parasites? Ecology 92:1559-1564. doi: 10.1890/10-1116.1

Tackenberg O (2003) Modeling Long-Distance Dispersal of Plant Diaspores by Wind. Ecol Monogr 73:173-189. doi: 10.2307/3100012 
1012 Taylor PD, Fahrig L, With KA (2006) Landscape connectivity: a return to the basics. In: 1013 Connectivity Conservation: maintaining connections for nature. Cambridge University Press, 1014 Cambridge, pp 29-43

1015 Taylor PD, Fahrig L, Henein K, Merriam G (1993) Connectivity Is a Vital Element of 1016 Landscape Structure. Oikos 68:571-573. doi: 10.2307/3544927

1017 Tewksbury JJ, Levey DJ, Haddad NM, Sargent S, Orrock JL, Weldon A, Danielson BJ, 1018 Brinkerhoff J, Damschen EI, Townsend P (2002) Corridors affect plants, animals, and their 1019 interactions in fragmented landscapes. Proc Natl Acad Sci 99:12923-12926. doi: $1020 \quad 10.1073 /$ pnas.202242699

1021 Thiele J, Buchholz S, Schirmel J (2017) Using resistance distance from circuit theory to model 1022 dispersal through habitat corridors. J Plant Ecol rtx004. doi: 10.1093/jpe/rtx004

1023 Tilman D, May RM, Lehman CL, Nowak MA (1994) Habitat destruction and the extinction 1024 debt. Nature 371:65-66. doi: 10.1038/371065a0

1025 Tischendorf L, Fahrig L (2000) On the usage and measurement of landscape connectivity. 1026 Oikos 90:7-19. doi: 10.1034/j.1600-0706.2000.900102.x

1027 Tscharntke T, Tylianakis JM, Rand TA, Didham RK, Fahrig L, Batáry P, Bengtsson J, Clough 1028 Y, Crist TO, Dormann CF, Ewers RM, Fründ J, Holt RD, Holzschuh A, Klein AM, Kleijn D, 1029 Kremen C, Landis DA, Laurance W, Lindenmayer D, Scherber C, Sodhi N, Steffan-Dewenter 1030 I, Thies C, van der Putten WH, Westphal C (2012) Landscape moderation of biodiversity 1031 patterns and processes - eight hypotheses. Biol Rev 87:661-685. doi: 10.1111/j.14691032 185X.2011.00216.x

1033 Tzoulas K, Korpela K, Venn S, Yli-Pelkonen V, Kaźmierczak A, Niemela J, James P (2007) 1034 Promoting ecosystem and human health in urban areas using Green Infrastructure: A literature 1035 review. Landsc Urban Plan 81:167-178. doi: 10.1016/j.landurbplan.2007.02.001

1036 van der Valk AG (1981) Succession in Wetlands: A Gleasonian Approach. Ecology 62:688696. doi: $10.2307 / 1937737$

1038 Vellend M, Myers JA, Gardescu S, Marks PL (2003) Dispersal of Trillium seeds by deer: 1039 implications for long-distance migration of forest herbs. Ecology 84:1067-1072. doi: $1040 \quad 10.1890 / 0012-9658(2003) 084[1067: D O T S B D] 2.0 . C O ; 2$

1041 Verheyen K, Vellend M, Calster HV, Peterken G, Hermy M (2004) Metapopulation dynamics 1042 in changing landscapes: a new spatially realistic model for forest plants. Ecology 85:33021043 3312. doi: 10.1890/04-0395

1044 Violle C, Navas M-L, Vile D, Kazakou E, Fortunel C, Hummel I, Garnier E (2007) Let the 1045 concept of trait be functional! Oikos 116:882-892. doi: 10.1111/j.0030-1299.2007.15559.x 
1046 Vittoz P, Engler R (2007) Seed dispersal distances: a typology based on dispersal modes and 1047 plant traits. Bot Helvetica 117:109-124. doi: 10.1007/s00035-007-0797-8

1048 Weiher E, Keddy PA (1995) The Assembly of Experimental Wetland Plant Communities. 1049 Oikos 73:323-335. doi: 10.2307/3545956

1050 Wilson DS (1992) Complex Interactions in Metacommunities, with Implications for 1051 Biodiversity and Higher Levels of Selection. Ecology 73:1984-2000. doi: 10.2307/1941449

1052 Wilson EO, Willis EO (1975) Applied Biogeography. In: Cody ML, Diamond JM (eds) 1053 Ecology and Evolution of Communities. Harvard University Press, Cambridge, pp 522-534 1054 Zacharias D, Brandes D (1990) Species Area-Relationships and Frequency: Floristical Data 1055 Analysis of 44 Isolated Woods in Northwestern Germany. Vegetatio 88:21-29. doi: $1056 \quad 10.2307 / 20038634$

1057 Zeller KA, McGarigal K, Whiteley AR (2012) Estimating landscape resistance to movement: 1058 a review. Landsc Ecol 27:777-797. doi: 10.1007/s10980-012-9737-0

1059 
1062 Fig. 1 Methods used to determine how landscape connectivity influences plant dispersal. (A)

1063 Study of potential dispersal (i.e. results of seed bank expression in habitat patches, integrating

1064 hence the local establishment process). White squares with diagonal lines represent focal habitat

1065 patches (patches of interest). Solid squares, triangles, circles and rhombus represent different

1066 plant species. Four measures of connectivity are employed: (1) Presencelabsence of corridors;

1067 (2) Euclidian distance; (3) Structural connectivity and (4) Potential functional connectivity.

1068 White squares represent landscape elements of the same habitat type than the focal habitat

1069 patches. Grey and black squares represent two different types of habitat patches. To determine

1070 potential functional connectivity, two different modelling approaches are commonly employed:

1071 (4*) least-cost path and $\left(4^{* *}\right)$ circuit theory. Both methods require parameterising resistance

1072 surfaces, with cost value reflecting the cost of species to traverse landscape features. In these

1073 cases, assigned costs to landscape features increase from white (highly permeable to dispersal)

1074 to black (slightly permeable to dispersal). (B) Study of actual dispersal (i.e. seed rain) White

1075 squares with diagonal lines represent habitat patches. Solid squares, triangles, circles and

1076 rhombus represent the seeds of different plant species. One measure of connectivity is

1077 employed: (5) Actual functional connectivity. Thicker arrows represent a higher rate of dispersal

1078 (i.e. higher connectivity), while thinner arrows represent a lower rate of dispersal (i.e. lower

1079 connectivity). 


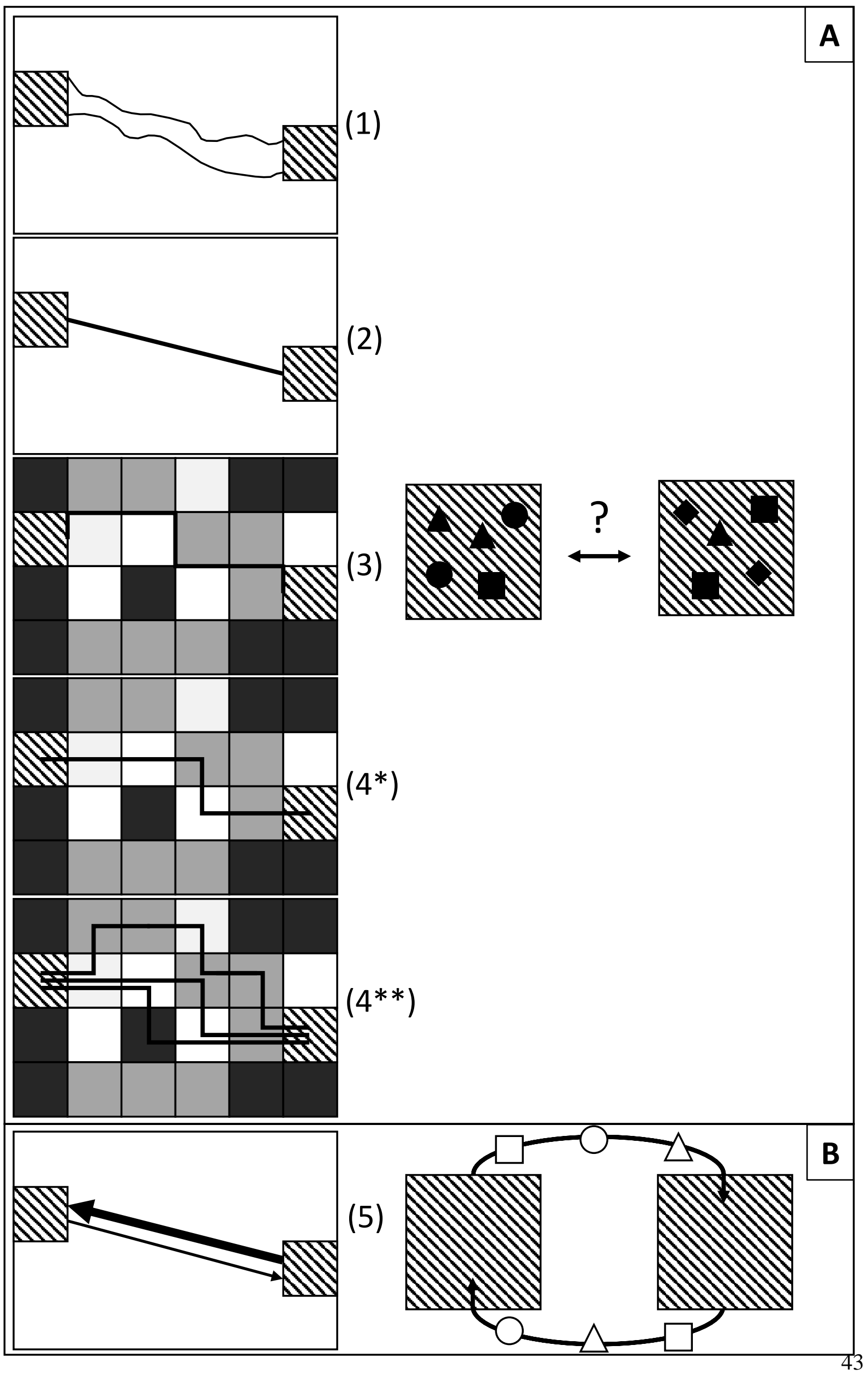


Box 1 Glossary

Structural connectivity: measure of connectivity based on the spatial position of patches independent of the attributes of the organism of interest (Tischendorf and Fahrig 2000; Bennett 2003; Taylor et al. 2006).

Potential functional connectivity: measure of connectivity that combines the physical attributes of the landscape with limited information about dispersal ability (Calabrese and Fagan 2004). This measure explicitly considers the behavioural responses of organisms to the physical structure of the landscape (Tischendorf and Fahrig 2000; Bennett 2003; Taylor et al. 2006).

Least-cost paths: modelling method to determine potential functional connectivity that assumes a unique path between two patches (represented by a solid line in Fig. 1), hypothesising that individuals perceive their environment in a way that leads them to "select" the optimal path (Adriaensen et al. 2003). The connectivity measure that results from this modelling method is an isolation measure called least-cost distance: the higher the least-cost distance, the lower connectivity.

Circuit theory: modelling method to determine to determine potential functional connectivity that evaluates all possible paths (represented by the three different solid lines in Fig. 1), assuming that dispersal follows random walks. The connectivity measure that results from this modelling method is an isolation measure called resistance distance: the higher the resistance distance, the lower connectivity (McRae et al. 2008).

Actual functional connectivity: measure of connectivity based on the observation of individuals moving through a landscape (Calabrese and Fagan 2004). This measure explicitly considers the behavioural responses of organisms to the physical structure of the landscape (Tischendorf and Fahrig 2000; Bennett 2003; Taylor et al. 2006). 
Box 2 Example of the Savannah River Site (SRS) experimental design for connectivity studies.

This experimental design is located in the Savannah River Site, a National Environmental Research Park in South Carolina, USA.

In 2000, eight 50-hectares landscapes were selected. These landscapes were composed of mature (40- to 50-year-old) forest, dominated by loblolly pine (Pinus taeda) and longleaf pine (Pinus palustris).

Within each landscape, five earlyFig. 2 One of the eight experimental landscapes in the SRS. successional habitat patches were created

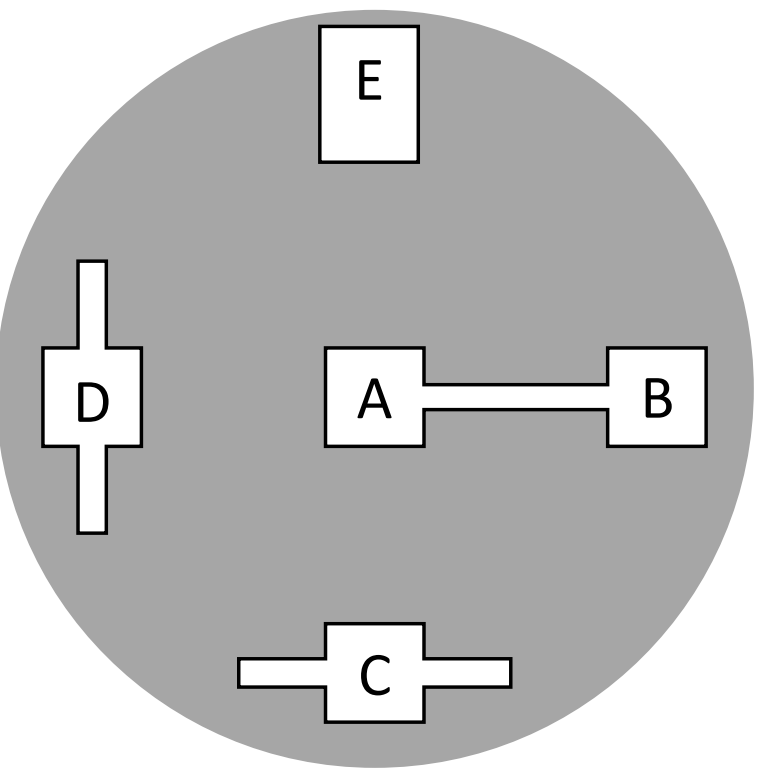
by cutting and removing all trees, and then burning the cleared areas. The patches included (Fig. 2): one central patch of 1 ha (A) and four peripheral patches (B, C, D, E) that were equal in distance $(150 \mathrm{~m})$ from the central patch, but with different structures (see below).

The experiment focused on two corridor functions. First, how a corridor impact connectivity through the following configuration: the central patch is connected to one peripheral patch (B) by a $150 \mathrm{~m}$ long and $25 \mathrm{~m}$ wide corridor and is not connected to the three other periphal patches $(\mathrm{B}, \mathrm{C}, \mathrm{D})$. The three other peripheral patches are equal in area to a patch plus a corridor (1.375 ha). Second, how a corridor impacts patch shape through the following manipulation of peripheral patches: in four landscapes, two of the remaining three periphical patches were winged (C and D) and one was rectangular $(E)$; in the other four landscapes, two periphical patches were retangular and one was winged.

The number of experimental landscapes used varied from six (Damschen et al. 2006) to eight (Tewksbury et al. 2002; Haddad et al. 2003, 2015; Levey et al. 2005; Damschen et al. 2008; Brudvig et al. 2009). This number was not clarified in Haddad et al. (2003). 
In our review, only the connectivity function of the corridor is discussed; thus, we only refer to connected patches versus unconnected patches. 
1084 Table 1 Synthesis of studies dealing with the effect of current and historical landscape connectivity on functional structure of plant communities.

1085 See Fig.1 for detailed explanations on the connectivity measures.

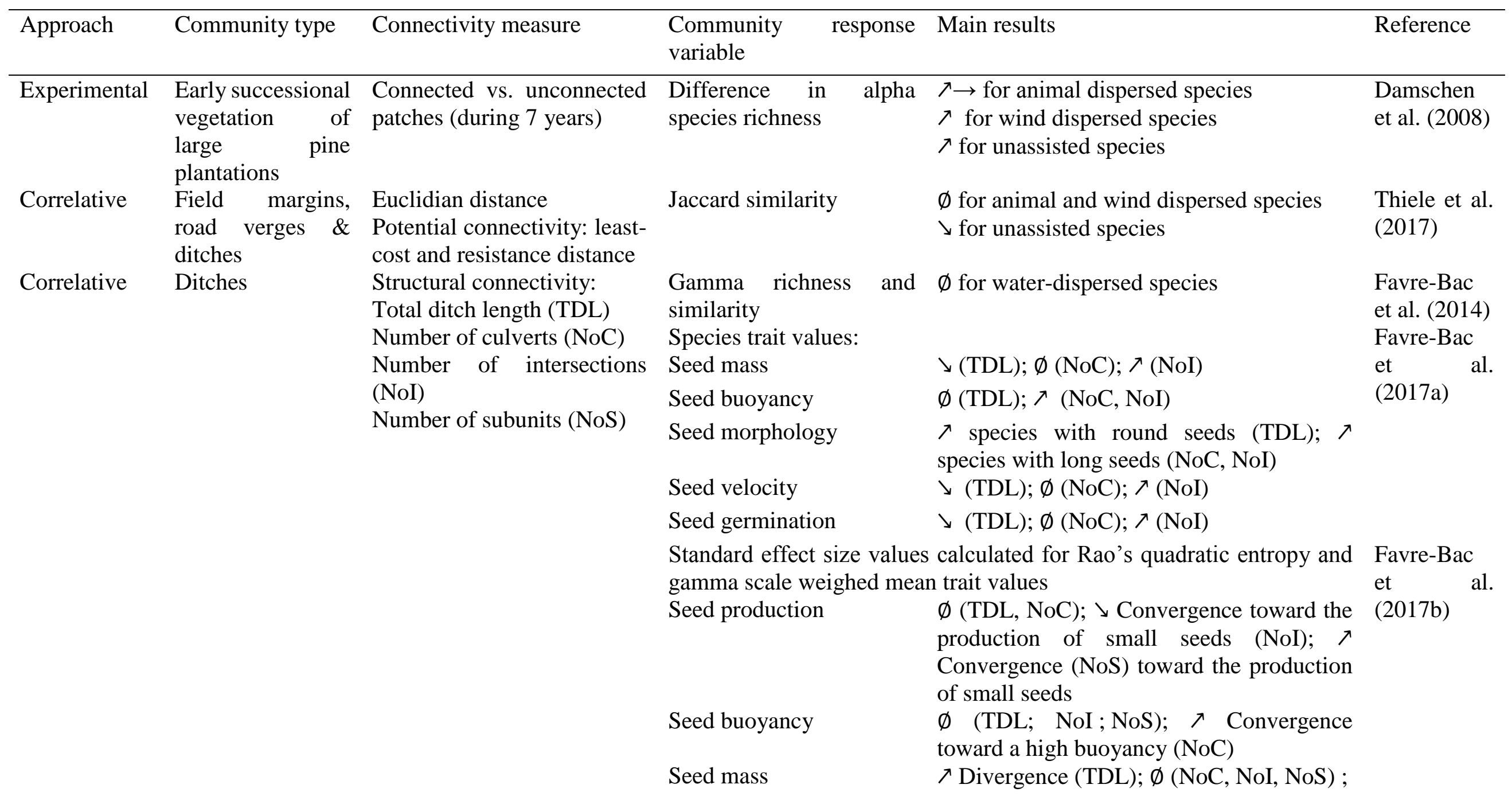




\begin{tabular}{|c|c|c|c|c|c|c|}
\hline \multirow[t]{5}{*}{ Correlative } & \multirow[t]{5}{*}{ Temperate forests } & \multirow[t]{5}{*}{$\begin{array}{l}\text { Structural connectivity (IFM } \\
\text { index) }\end{array}$} & \multirow[t]{5}{*}{$\begin{array}{l}\text { Trait values of emergent } \\
\text { groups to connectivity } \\
\text { loss }\end{array}$} & $\begin{array}{l}\text { Sensitive emergent } \\
\text { group: }\end{array}$ & $\begin{array}{l}\text { Resistant emergent } \\
\text { group: }\end{array}$ & \multirow[t]{5}{*}{$\begin{array}{l}\text { Kolb and } \\
\text { Diekmann } \\
(2005)\end{array}$} \\
\hline & & & & $\begin{array}{l}\text { Unassisted dispersal } \\
\text { Few and heavy } \\
\text { seeds }\end{array}$ & $\begin{array}{l}\text { Assisted dispersal } \\
\text { Many and thin seeds }\end{array}$ & \\
\hline & & & & High clonality & No or little clonality & \\
\hline & & & & $\begin{array}{l}\text { Short seed bank } \\
\text { longevity }\end{array}$ & $\begin{array}{l}\text { Long seed bank } \\
\text { longevity }\end{array}$ & \\
\hline & & & & Small height & Tall & \\
\hline Correlative & Grasslands & $\begin{array}{l}\text { Structural connectivity (IFM } \\
\text { index) }\end{array}$ & $\begin{array}{l}\text { Species richness of } \\
\text { emergent groups }\end{array}$ & \multicolumn{2}{|c|}{$\begin{array}{l}\nearrow \text { for perennial rosette } \\
\varnothing \text { for orchids, half-rosette and annuals } \\
\text { species }\end{array}$} & $\begin{array}{l}\text { Adriaens et } \\
\text { al. (2006) }\end{array}$ \\
\hline Correlative & $\begin{array}{l}\text { Dry calcareous } \\
\text { grasslands }\end{array}$ & $\begin{array}{l}\text { Structural connectivity (IFM } \\
\text { index) }\end{array}$ & $\begin{array}{l}\text { Probability of occurrence } \\
\text { in response to } \\
\text { connectivity }\end{array}$ & \multicolumn{2}{|c|}{$\begin{array}{l}\nearrow \text { for species with low seed number } \\
\varnothing \text { for species whatever their dispersal mode } \\
\text { (wind-dispersal or not), seed mass or seed } \\
\text { bank longevity } \\
\nearrow \text { for short-living species } \\
\varnothing \text { for clonal species }\end{array}$} & $\begin{array}{l}\text { Evju et al. } \\
(2015)\end{array}$ \\
\hline Correlative & Heathlands & $\begin{array}{l}\text { Structural connectivity (IFM } \\
\text { index) }\end{array}$ & $\begin{array}{l}\text { Species richness in the } \\
\text { different categories of the } \\
\text { seed longevity index }\end{array}$ & \multicolumn{2}{|c|}{$\nearrow$ for species with short seed bank longevity } & $\begin{array}{l}\text { Piessens et } \\
\text { al. (2004) }\end{array}$ \\
\hline Correlative & Heathlands & $\begin{array}{l}\text { Structural connectivity (IFM } \\
\text { index) }\end{array}$ & $\begin{array}{l}\text { Regression coefficient } \\
\text { resulting from the logistic } \\
\text { regression between patch } \\
\text { occupancy for each species } \\
\text { as explained by } \\
\text { connectivity intensity }\end{array}$ & \multicolumn{2}{|c|}{$\begin{array}{l}\nearrow \text { for species with short seed bank longevity } \\
\varnothing \text { for species whatever their mean plant } \\
\text { height, seed mass, dispersal mode, growth } \\
\text { form, self-compatibility, clonal growth } \\
\text { form and seed number }\end{array}$} & $\begin{array}{l}\text { Piessens et } \\
\text { al. (2005) }\end{array}$ \\
\hline
\end{tabular}




\begin{tabular}{|c|c|c|c|c|c|}
\hline Correlative & Temperate forests & $\begin{array}{l}\text { Structural connectivity } \\
\text { (modified version of IFM } \\
\text { index that incorporates patch } \\
\text { age) }\end{array}$ & $\begin{array}{l}\text { Regression coefficient } \\
\text { resulting from the logistic } \\
\text { regression between patch } \\
\text { occupancy for each } \\
\text { species as explained by } \\
\text { connectivity intensity }\end{array}$ & $\begin{array}{l}\nearrow \text { for vertebrate and wind-dispersed species } \\
\nearrow \text { for species with low seed production } \\
\nearrow \text { for species with small height } \\
\varnothing \text { for species whatever their life cycle } \\
\text { duration }\end{array}$ & $\begin{array}{l}\text { Verheyen et } \\
\text { al. (2004) }\end{array}$ \\
\hline \multirow[t]{2}{*}{ Correlative } & \multirow[t]{2}{*}{ Urban - ruderals } & \multirow{2}{*}{$\begin{array}{l}\text { Structural connectivity (IFM } \\
\text { index) }\end{array}$} & \multicolumn{2}{|c|}{ Trait values of response groups to connectivity: } & \\
\hline & & & $\begin{array}{l}\text { Terminal velocity } \\
\text { Number of seeds } \\
\text { Seed mass }\end{array}$ & $\begin{array}{l}\text { Sensitive }>\text { resistant species } \\
\text { Sensitive }<\text { resistant species } \\
\text { Sensitive }=\text { resistant species }\end{array}$ & \\
\hline Correlative & Grasslands & $\begin{array}{l}\text { Current }(\mathrm{C}) \text { and historical } \\
(\mathrm{H}) \text { structural connectivity } \\
\text { (IFM index) } \\
1 \mathrm{~km} \text { radius } \\
2 \mathrm{~km} \text { radius }\end{array}$ & Proportion of species & $\begin{array}{l}\varnothing \text { for animal-, wind- dispersed and } \\
\text { unassisted species } \\
\varnothing \text { for species whatever their seed size } \\
\varnothing(\mathrm{C}) ; \searrow(\mathrm{H}) \text { for long seed bank persistence } \\
\text { species } \\
\nearrow(\mathrm{C}) ; \varnothing(\mathrm{H}) \text { for annual plants } \\
\varnothing(\mathrm{C}) ; \searrow(\mathrm{H}) \text { for perennials with or without } \\
\text { clonality at } 1 \mathrm{~km} \text { scale. } \\
\varnothing(\mathrm{C}) \text { for perennials with or without clonal } \\
\text { ability at } 2 \mathrm{~km} \text { scale } \\
\searrow(\mathrm{H}) \text { for perennials without clonal ability } \\
\text { at } 2 \mathrm{~km} \text { scale }\end{array}$ & $\begin{array}{l}\text { Lindborg } \\
(2007)\end{array}$ \\
\hline
\end{tabular}




\title{
Effect of landscape connectivity on plant communities: a review of response patterns
}

\author{
Uroy L. ${ }^{1}$, Ernoult A. ${ }^{1}$, Mony C. ${ }^{1}$
}

1: UMR CNRS ECOBIO, University of Rennes, Avenue du Général Leclerc, 35042 Rennes

Cedex, France

\section{Appendix S1 Methods}

We systematically reviewed articles to assess whether and how landscape connectivity affects the assembly of plant communities. Using Web of Science and Google Scholar to gather publications using the following keywords: landscape connectivity, habitat isolation, corridors and plants. Because ecosystem functioning is completely different in tropical systems, we excluded these studies, only considering studies conducted in temperate systems. We also excluded studies that focus on fragmentation (i.e. that are conducted in a fragmented landscape context); that is, when it is not possible to disentangle the effects of decreased connectivity (variable of interest) and decreased habitat area. We only considered studies that: i) manipulated connectivity through the presence (or absence) of an experimentally-created corridor between two habitat patches for experimental approaches, and ii) measured connectivity in a quantitative manner (via the use of indices) for correlative approaches. Quantitative connectivity assessments were based on isolation metrics such as Euclidean distance, structural connectivity indices (see various examples in the main text), least-cost distance or resistance distance. We selected studies that focused on how landscape connectivity affected plants at the community level. Within this framework, we included studies with taxonomic approaches (i.e. looking at the composition and diversity of plant communities) and trait-based approaches (i.e. looking at the composition and diversity of traits). These studies assessed plant community response through: i) analysis of individual species responses across most species at the community level, and ii) aggregated measures across most species of a community. More specifically, only the following measures were extracted from articles that provided: i) taxonomic and ii) trait-based approaches:

i) Taxonomic approaches: alpha diversity (species richness, species density or species abundance), beta diversity (Jaccard similarity index) and gamma diversity (gamma species richness)

ii) Trait-based approaches:

a. Dispersal mode approach: analyses similar to the taxonomic approach but per dispersal mode, proportion of species per dispersal mode and indicators for species sensitivity to connectivity (probability of occurrence in response to connectivity, regression coefficient resulting from the logistic regression between patch occupancy for each species as explained by connectivity intensity)

b. Emergent groups approach: trait values of emergent groups and species richness of emergent groups

c. Response traits approach: indicators for species sensitivity to connectivity (probability of occurrence in response to connectivity, regression coefficient 
resulting from the logistic regression between patch occupancy for each species as explained by connectivity intensity), species richness in the different categories of the seed longevity index, proportion of species characterised by a trait, trait value of response groups to connectivity and species trait values

d. Community weighted mean traits and functional diversity approach: functional gamma diversity (standard effect size values calculated for Rao's quadratic entropy traducing functional divergence or convergence) and gamma aggregated mean trait values (gamma scale weighed mean trait values, indicating the mean value towards which traits converged)

1142 Concerning actual dispersal approaches, we included studies at the species level because very 1143 few studies have assessed the actual dispersal of communities in relation to connectivity. 